\title{
EL CARNAVAL DE BACHAJÓN
}

\section{Cultura y naturaleza: dinámica de un ritual tzeltal}

\author{
Aurore BEcQueLin-MoNoD \\ Alain BretoN \\ Universidad de París X-Nanterre
}

Este artículo se refiere a la fiesta de Carnaval en un pueblo indigena de la zona tzeltal septentrional: Bachajón, agencia municipal del Municipio de Chilón, en el Estado de Chiapas (México)*.

El Carnaval, que dura cinco días, es celebrado sólo por una parte del pueblo, ya que de los dos barrios, San Sebastián en el norte y San Jerónimo en el sur, sólo San Sebastián ha conservado una estructura tradicional, manteniendo sus autoridades precoloniales y guardando ciertas tradiciones socio-religiosas.

La descripción detallada de este Carnaval nos parece necesaria en la medida en que la influencia predominante del sistema tradicional indígena del periodo colonial en un barrio, coexiste con la influencia predominante del "ayuntamiento" español dentro del otro barrio deI mismo pueblo. Esto nos recuerda que Chiapas ofrece un gran número de ejemplos diferentes de transformación cultural: en un extremo, la apariencia conservadora cubre una estructura social completamente transformada en la actualidad; en el extremo contrario, bajo la apariencia de ladinización — vestido, habitación - subsisten numerosos elementos arcaicos, y entre estas dos formas, un gran número de casos intermedios son demostrados en la literatura etnográfica.

* El estudio del Carnaval de Bachajón se realizó en el transcurso de las investigaciones lingüísticas y etnológicas realizadas en Chiapas, en cooperación con los trabajos de la Misión Arqueológica Francesa en Toniná. Agradecemos al Sr. Jérôme Sautier, quien aceptó nuestra petición de efectuar una investigación de documentos en México y participarnos sus resultados. Agradecemos a la Srita. Leticia Méndez M. por efectuar la traducción de este artículo del francés al español.

La traducción fue revisada por la Comisión Editorial del Centro de Estudios. Mayas (N. E.). 
Presentaremos, en primer lugar, el cuadro sociológico de la fiesta y en la segunda parte, una descripción detallada de ésta.

\section{BACHAJON}

\section{Generalidades}

La región de Bachajón (tzeltal norte) se extiende dentro de la vertiente septentrional de los Altos de Chiapas, a una altitud media de $900 \mathrm{~m}$., que corresponde al límite superior de la tierra caliente.

El tzeltal pertenece a la familia lingüística maya, tiene un parentesco estrecho con el chol y con el tojolabal, y más particularmente con el tzotzil de las Tierras Altas (Kaufman 1962:126-127). Es hablado por 80000 personas; presenta variaciones dialectales que diferencian cada comunidad, de la misma forma que el vestido y ciertas costumbres específicas.

Bachajón cuenta con una población aproximada de 20000 personas y con un territorio de cerca de $1,000 \mathrm{~km}^{2}$. Es la que presenta una mayor densidad de población y la más grande de las comunidades tzeltales; el poblado no cuenta más que con 1,000 habitantes permanentes pero el resto de la población está dispersa, instalada sobre las tierras agrícolas y repartida entre un cierto número de linajes patrilineales. La administración ha dividido este "habitat rural" en rancherías de una importancia variable, que corresponden en raras ocasiones a la organización tradicional de la tierra y de los grupos humanos.

El poblado de Bachajón (centro de la comunidad), está situado en el seno de una región montañosa bastante accidentada. La alternancia de cordilleras y depresiones es característica del conjunto del territorio. Hacia el noreste, las cadenas montañosas descienden progresivamente hasta las tierras cálidas a $300 \mathrm{~m}$. de altitud.

Los tipos de vegetación varían, desde el bosque de coníferas hasta el bosque tropical, en la medida que la altitud decrece. El régimen pluvial presenta dos periodos claramente definidos: una estación húmeda de mayo a octubre, y una estación seca de noviembre a abril. Durante la primera mitad de esta última, es frecuente la caída de aguaceros ocasionados por los "nortes"; éstos son irregulares y de intensidad variable. Las pronunciadas pendientes, la erosión, el agotamiento natural y cultural del suelo, afectan en la práctica el desarrollo de una agricultura de subsistencia (maíz y frijol) sobre la base de un sistema ancestral de roza. 
Los estudios glotocronológicos permiten considerar que los tzeltales ocupan esta zona desde principios del periodo Clásico reciente de la civilización maya (situado alrededor del año 500 de nuestra era), periodo a través del cual se desarrolló el gran centro ceremonial de Toniná, sitio vecino a Bachajón, excavado en 1972 y en 1973 por P. Becquelin y C. Baudez. Las investigaciones recientes nos ilustran sobre las características regionales de la organización social de los grupos de esa época. Con la caída de la civilización maya (consumada definitivamente en el siglo $\mathrm{x}$ ) comienza el periodo postclásico y 600 años de historia, que aún se encuentra poco conocida (Calnek, s.f), hasta la conquista española.

Se suponía que durante este último periodo las sociedades locales se presentaban bajo la forma de pequeñas jefaturas independientes; las poblaciones vivían muy dispersas sobre la totalidad del territorio, caracterizado por una red de "pueblos-centro".

A pesar de la ignorancia casi total en lo que concierne a la organización espacial, así como las relaciones políticas y económicas que ellas mantuvieron, en el estado actual de nuestros conocimientos se puede eliminar la hipótesis de un poder centralizado, dominante, que se pueda comparar con el Estado quiché contemporáneo de las tierras altas de Guatemala.

La región fue conquistada en 1525, por las tropas de Diego de Mazariegos, después de un primer fracaso de Luis Marín en 1523. Las antiguas jefaturas (o parcialidades) fueron repartidas entre los conquistadores bajo la forma de encomiendas privadas, de las cuales algunas debieron transmitirse hasta el final del S. Xvir. Es probable que estas jefaturas conservaran su autonomía territorial durante más de cuarenta años, antes de ser reagrupadas dentro de pueblos coloniales bajo la influencia y el control de los misioneros dominicos, de acuerdo con la política de reducción.

\section{Organización socio-territorial}

\section{A. La Comunidad}

La comunidad de Bachajón se encuentra actualmente dividida en dos barrios; para marcar sus límites existe una zanja que corta longitudinalmente el conjunto del territorio, incluyendo el centro del pueblo. El barrio de San Sebastián corresponde a la parte norte, y el barrio de San Jerónimo a la parte sur, no obstante lo cual la administración concierne a una sola organización, unificada dentro del 
Ayuntamiento Constitucional. Participan en forma "igualitaria" en las decisiones que afectan al conjunto de la comunidad, o para la celebración de ciertas fiestas, a través de sus representantes respectivos. Sin embargo, se diferencian por una organización interna y ciertos rasgos culturales propios (Fig. 1).

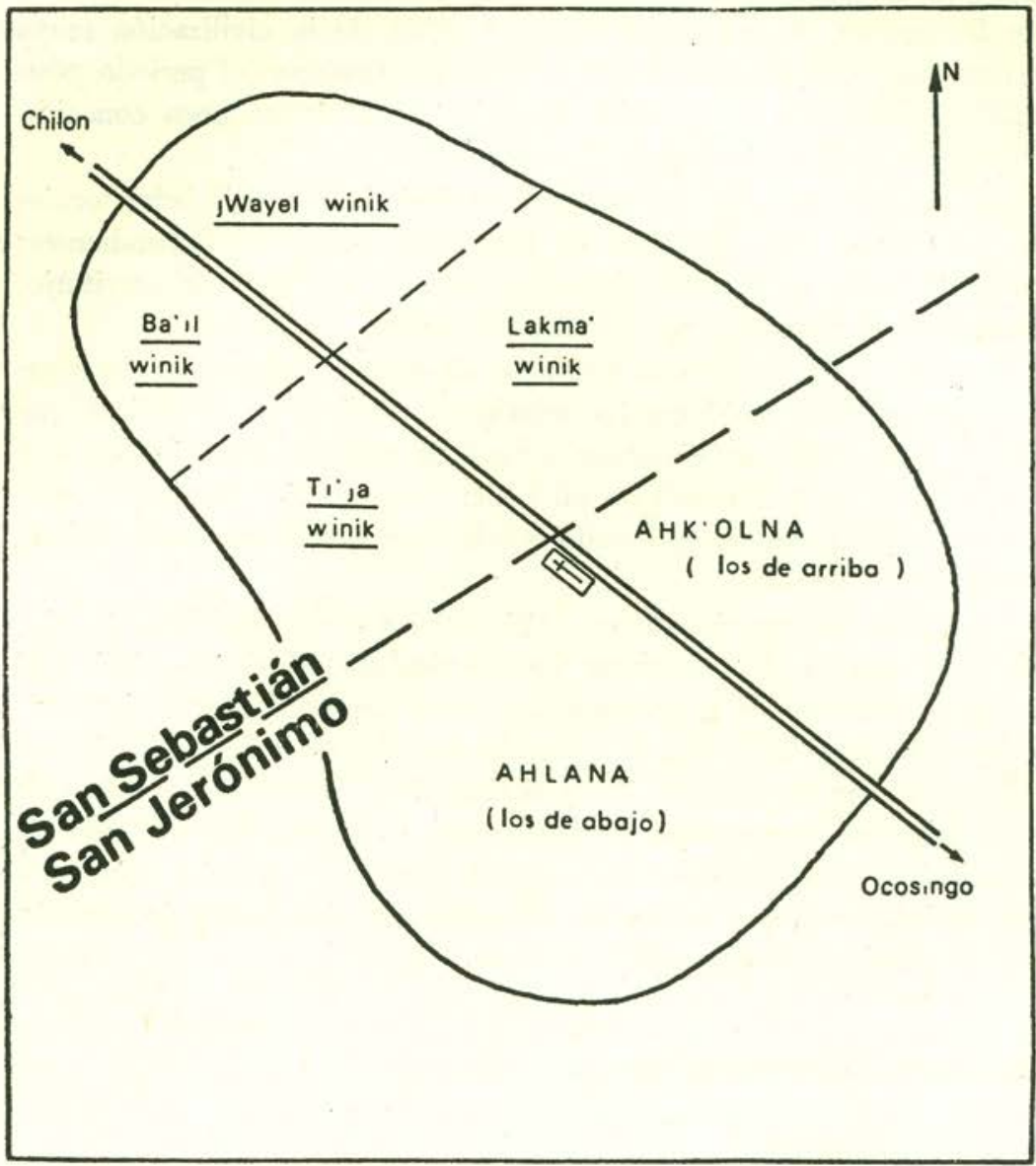

Figurs 1. Esquema de la división Territorial en el pueblo de Bachajón.

San Jerónimo tenía hasta fecha reciente una estricta división de su población y de su territorio en dos mitades endógamas, fundada ideológicamente sobre la oposición arriba/abajo (en tzeltal ank'ol/ ahlan). 
"Los de abajo" (ahlana) provienen del grupo más antiguo, cuya historia se confunde con la propia historia de la comunidad, en tanto que remonta sobre sus fuentes, hasta el origen de su formación.

"Los de arriba" (ahk' olna) son originarios de un grupo que se estableció posteriormente (a partir del siglo xvm). Llevan aún el nombre de naburios, deformación de laborios, término que tiene referencia directa con una categoría socioeconómica de la sociedad colonial (trabajadores libres en las haciendas).

Las diferencias económicas y sociales (endogamia) oponen a los dos grupos; sin embargo, éstas tienden a atenuarse. En el interior del barrio de San Jerónimo, los límites se marcan por la carretera que sirve de división entre las mitades (en el pueblo, la calle principal). Cada una de ellas posee sus propias autoridades rituales - dos principales- encargadas de la organización de las fiestas y de escoger los representantes anuales.

San Jerónimo es el más aculturado de los dos barrios; su población muestra un mayor dinamismo y una cierta apertura en relación a los cambios. Es dentro de este barrio, que una misión jesuita importante se implantó en 1958.

En cuanto a San Sebastián, tiene una población homogénea, cuyo origen se pierde en el pasado prehispánico; ha permanecido hasta el presente renuente a las iniciativas misioneras y modernistas en general. Se reparte en cuatro secciones llamadas "kalpul" (término de origen

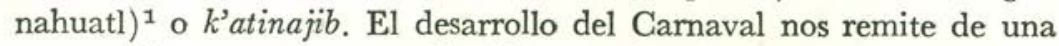
manera directa a esta organización cuatripartita específica del barrio San Sebastián.

Señalamos, para recordar, la oposición y el antagonismo que mar can las relaciones entre los dos barrios dentro de la organización comunitaria:

La línea de división, que se limpia frecuentemente, materializa la separación de dos terrenos distintos, entre los cuales no es posible la existencia de ninguna transacción de tierras o de hombres; cada barrio forma un ejido independiente, teniendo su propia historia y sus propias autoridades.

En el aspecto matrimonial, los barrios practican una regla de endogamia, en otro tiempo menos estricta que en la actualidad. Las recientes y escasas uniones exógamas son aún casos excepcionales y que tuvieron siempre como resultado el desplazamiento de la mujer.

1 El término kalpul es empleado por los tzeltales de Bachajón. Adoptamos la letra $k$ para no darle $a$ priori el sentido que tiene este término en el Altiplano Central de México. 
El hombre que abandonase su barrio de origen se vería desposeído de todos sus bienes, al mismo tiempo que sería rechazado por su barrio de adopción.

Antiguamente los dos barrios se oponían por su vestido y aún en el presente a través del idioma (se observan marcadas diferencias dialectales tanto en el plan fonético como en el uso exclusivo de ciertas palabras, por ejemplo, de términos de parentesco).

\section{B. San Sebastián}

Los bachajontecos siguen una regla de filiación patrilineal que concuerda en gran medida con el modo de residencia (patrilocal) y la transmisión de bienes y de status; ella encuentra su expresión en un sistema terminológico de tipo Omaha, reconocido como representante de una forma estable de organización patrilineal.

\section{Los Linajes}

De manera general, la población de la comunidad se reparte entre un centenar de patrilinajes, localizados (o semilocalizados) y exógamos. En forma particular, en el barrio de San Sebastián, que nos sirve como cuadro de referencia, se incorporan 44 de esos grupos, que le son exclusivos.

Cada patrilinaje participa dentro de un doble sistema patronímico cuyo principio es muy extendido en las comunidades indígenas de Chiapas, perfectamente conocido y mencionado en numerosos estudios (entre otros: Villa Rojas, 1947; Pozas, 1959; Siverts, 1960; Guiteras Holmes, 1961; Vogt, 1969). El patrilinaje se define por un nombre tzeltal ( $j o l$ sbihil: "la cabeza del nombre"), utilizado solamente como término de referencia, cuando la discusión se inicia sobre el problema de tierras y por un nombre de origen español (apellido), que se conserva como el medio principal de identificación.

Los patronímicos tzeltales y los apellidos se combinan de tal suerte que a estos últimos se encuentran asociados en forma exclusiva de uno a veinte nombres indígenas. ${ }^{2}$

Los linajes denominados de esta manera son de hecho, ${ }^{3}$ los propietarios de la tierra, roturada y trabajada por sus ancestros agnados,

2 Un estudio más completo de este doble sistema patronímico se encuentra en Breton, s.f.: $106-115$ y $252-260$.

3 En términos legales, la propiedad de la tierra de la comunidad es del Estado, bajo la forma institucional del ejido. 
y donde teóricamente cada individuo masculino puede cultivar, establecer su residencia y/o transmitir la tierra en tanto que él es miembro de un grupo patronímico. En realidad, existe una sensible desigualdad en el reparto del patrimonio de la tierra, de un linaje a otro, que compensa en una cierta medida la práctica generalizada del préstamo.

La propiedad de la tierra es inalienable y las tierras propias del linaje constituyen un territorio específico donde se permite el cultivo en cooperación de los miembros del grupo y en el cual ellos residen. Dentro de la forma de residencia se traducen las diferentes formas de cooperación económica (un sitio simple corresponde a la familia nuclear; un sitio compuesto corresponde a la familia extendida; un grupo de sitios reúne a los miembros de un linaje o un segmento aislado de un linaje). ${ }^{4}$ Además, los miembros de un linaje comparten con frecuencia una casa en el pueblo, residencia que sólo ocupan el domingo o con motivo de las fiestas, que son los días de gran actividad religiosa y comercial.

Los linajes son rigurosamente exógamos. Las estrategias matrimoniales se definen a la vez por los elementos negativos (si se toma en consideración la terminología de parentesco de tipo Omaha) y por elección preferencial en términos de distancia geográfica 'uno se casa dentro de su propio grupo de vecindad). En resumen, el patrilinaje asegura a sus miembros el acceso y el empleo de la tierra, principal medio de producción, y define al mismo tiempo las modalidades de alianza; él controla todo lo referente a la reproducción material del grupo.

\section{Los kalpules}

En Bachajón, contrariamente a la mayoría de las comunidades de Chiapas, donde podemos descubrir su existencia (terminológica), el kalpul no es ni un barrio ni una mitad. Es una categoría independiente, integrada en una organización cuatripartita que ocupa en la organización social en general un nivel intermedio entre los linajes exór gamos y el barrio endógamo. La pertenencia a uno de los cuatro kalpules se determina por nacimiento, y cualquier individuo, hombre o mujer, pertenece obligatoriamente al kalpul de su padre y de sus ancestros agnados.

4 Ciertos linajes son particularmente extendidos y se presentan bajo la forma de segmentos localizados aisladamente los unos con relación a los otros. La solidaridad en su interior corresponde a la función de distancia genealógica entre sus miembros y la distancia geográfica que los separa. 
La primera definición del kalpul es epónima. Los nombres completos de los cuatro kalpules son los siguientes:

lakma' winik: La etimología de lakma no es segura. El término winik significa "hombre"

ti'ja' winik: "El hombre de la orilla del río"

ba'il winik: "Hombre topo"

wayel winik: "Hombre dormido" (que procede de way que significa "dormir" o "sueño").

Aun cuando no se encuentre una fórmula específica, y a pesar de la ausencia de mitos de origen, estos nombres sugieren que se puede tratar de aquellos cuatro ancestros míticos, epónimos. El primero, lak$m a$ ' winik, es llamado muk'ul kalpul (el gran kalpul) y lleva el mismo título que su jefe, considerado como el primogénito o bankil, por oposición a los otros tres, llamados bik'it kalpul o ijts'in (pequeños kalpules o menores). La persistencia de esta clasificación, fundada sobre ciertos criterios clave dentro de la organización del universo tzeltal (maya) antiguo, añadida al hecho de que el nombre lakma' designaba una de las tres "parcialidades" o jefaturas prehispánicas en los primeros documentos, y después uno de los barrios de la comunidad colonial, comprueba en cierta forma la profundidad histórica de esta organización cuatripartita.

En tzeltal las personas de un mismo kalpul se llaman k'atinajib. Veremos más adelante cómo el kalpul o k'atinajibal puede definirse a través de las funciones ejercidas por el hombre que es responsable: el k'atinab o ts'umbajon. Precisemos desde este momento que el kalpul es vivido como un grupo de descendencia en el seno del cual la relación de reciprocidad juega un papel primordial: la actividad ritual perpetuada por sus miembros asegura a ellos la protección de sus ancestros por intermedio del ts umbajon.

Cada kalpul integra un número variado de patrilinajes que le son en su mayoría exclusivos. La definición indígena según la cual "al kalpul pertenecen como veinte casas", nos conduce a este aspecto colectivo -entendiéndose aquí "casa" como el conjunto de habitaciones compartidas por los miembros de un mismo grupo patronímico tzeltal (es decir linaje)-. Los kalpules no tienen ninguna función matrimonial, ellos no intervienen en la elección del cónyuge. Sus relaciones se asientan dentro de otro registro y son marcados con el doble sello de la rivalidad (en materia de brujería, por ejemplo) y de la alianza ritual. Esta última será estudiada a continuación, más espe- 
cíficamente, a través del estudio del sistema de cargos y de la fiesta del Carnaval.

La definición territorial del kalpul permite, en fin, precisar el espacio de la fiesta y la función simbólica del pueblo. Dentro de las rancherías y sobre el conjunto del territorio agrícola, el kalpul, en efecto, no tiene un establecimiento territorial preciso; se encuentra localizado en la medida en que los miembros del linaje que dependen de él están presentes.

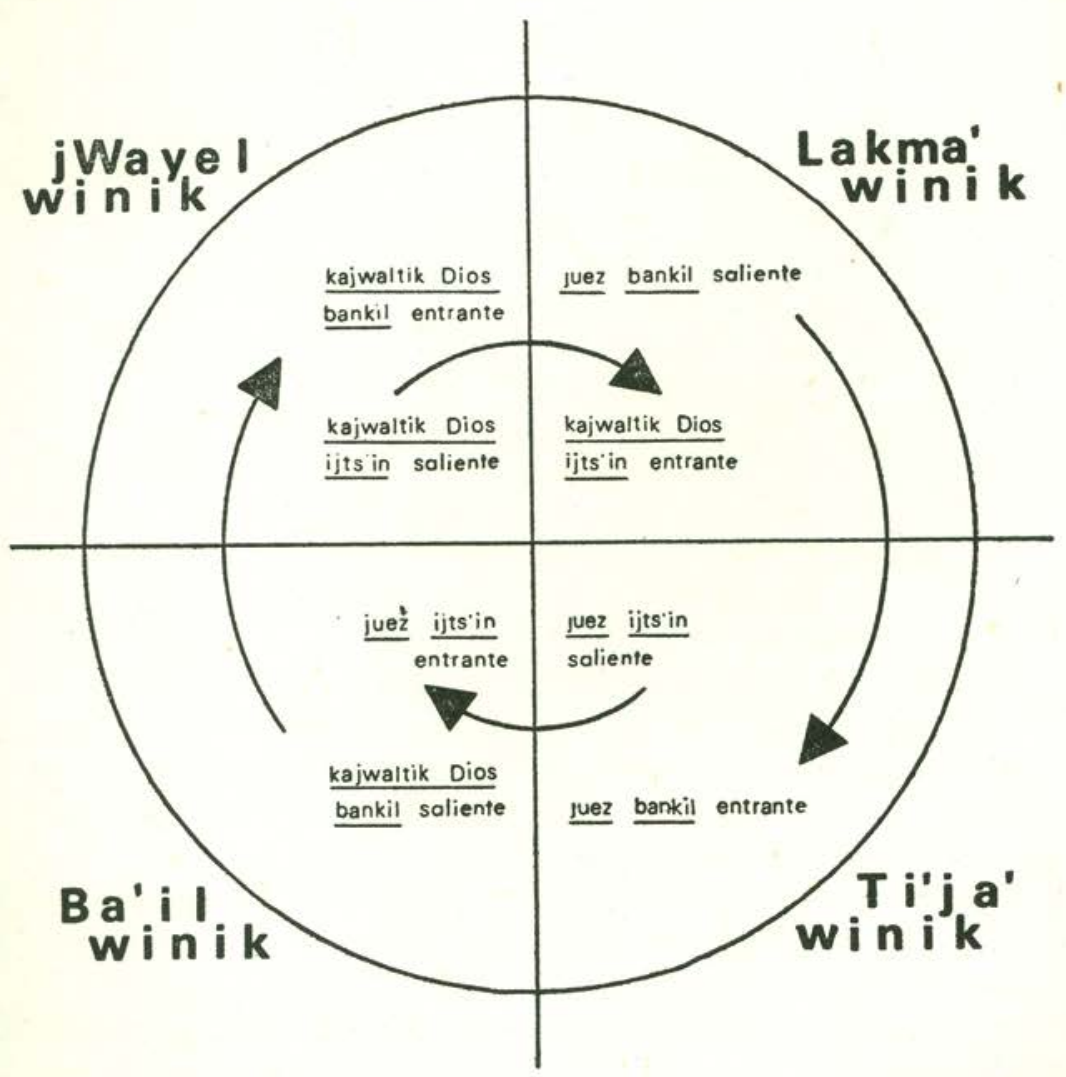

FIGURA 2.-Posiciones teóricas de los cargos de capitanes para una fiesta de Carnaval.

* La presencia simultánea de los cargos de bankil y de ijts'in para cada categoría de capitanes en los dos kalpules adyacentes y el sentido de la rotación expresado por los términos "saliente" y "entrante", permite al sistema cuatro combinaciones posibles de los dos parámetros kahwaltik Dios y juez. 
Por lo contrario, en el centro de la comunidad, la parte del pueblo que corresponde al barrio de San Sebastián se encuentra dividida en cuatro secciones correspondientes (Fig. 1). Los límites son fijados y conocidos por todos: uno construye su casa (en el pueblo) dentro del propio territorio del kalpul al que pertenece, ya sea residencia principal o secundaria. Los hombres que viven en las rancherías y que no tienen casa en el pueblo son hospedados por sus k'atinajib (miembros de su $k a l p u l)$, parientes, aliados o amigos.

\section{Sistema de cargos y poder tradicional}

En tanto que "comunidad", Bachajón estuvo sometida desde la época colonial a un doble control civil y religioso. En la actualidad, conserva las instituciones originadas en esta época, de inspiración española, que se presentan bajo la forma de:

\section{Ayuntamiento Constitucional Mayordomías}

La primera asegura el poder político y administrativo de la comunidad en el seno de la organización municipal (Bachajón es una agencia del Municipio de Chilón); se constituye sobre una jerarquía de cargos civiles llamados "justicias", a la cabeza de la cual figuran el "presidente municipal" y el "juez".

Las segundas, creadas por el clero español para garantizar la presencia de la Iglesia y promover el culto, han caído ahora prácticamente en desuso y su papel se limita a celebrar algunas fiestas, ya que fueron suplantadas desde hace algunos años por una nueva organización, la Acción Católica.

Estas instituciones tienen por principio común el reclutar a sus respectivos miembros entre la población de los dos barrios. No intervienen sino en una forma marginal en las fiestas del Carnaval.

$\mathrm{Al}$ lado de estas instancias "comunitarias", aún persiste una organización religiosa tradicional que, aunque alterada por diferentes rasgos de origen hispánico, aparece dentro de sus funciones y su estructura como más antigua y autóctona. Dicha organización, llamada genéricamente "capitanías" (por oposición a las justicias y a las mayordomías), tiene un papel central en el desarrollo de las fiestas de Garnaval y se articula, dentro del barrio de San Sebastián, con el contexto del linaje que se ha descrito anteriormente. Depende de las instancias tradicionales del poder bajo el control de las autoridades 
gerontocráticas o, según la expresión de Aguirre Beltrán (1953: 136), del "Gobierno de Principales".

La clasificación indígena distingue dentro de este sistema cinco niveles de cargos jerárquicos, organizados de acuerdo a tres modalidades temporales:

\begin{tabular}{ccccc}
\hline $\begin{array}{c}\text { Cargos Anuales } \\
\text { (Capitanes) }\end{array}$ & Cargos de Larga & Duración & $\begin{array}{c}\text { Cargos Permanentes } \\
\text { (kananlum) }\end{array}$ \\
\hline Santo & Carnaval & Caporal & Alguacil & $\begin{array}{c}\text { ts'umbajon } \\
\left(k^{\prime} \text { atinab }\right)\end{array}$ \\
NIV. 1 & NIV. 2 & NIV. 3 & NIV. 4 & NIV. 5 \\
\multicolumn{2}{l}{ Sometidos a rotación } & No sometidos a rotación \\
\hline
\end{tabular}

Esta jerarquía no requiere actualmente el paso obligatorio de un nivel a otro inmediatamente superior (a excepción de 4 a 5). Regresaremos posteriormente sobre los conceptos de rotación y de cargos fijos.

\section{Capitanes}

Los cargos de "capitanes" son anuales; los voluntarios que ya se han dado a conocer anteriormente son escogidos por los ts umbajonetik (dentro del kalpul respectivo) de acuerdo a los criterios de personalidad o de capacidad económica. Es en efecto sobre estos cargos que se apoyan todas las responsabilidades materiales de la organización de las fiestas: los "capitanes de Santo" son responsables de las fiestas del santo para el cual han sido nombrados; los "capitanes del Carnaval" para aquellas del Carnaval. Los gastos indispensables para la

5 El término español de "principal" es de empleo frecuente en Bachajón, y se aplica para designar diferentes funciones asumidas por hombres mayores, quienes poseen una gran experiencia en las actividades públicas, por el hecho de haber tenido numerosas responsabilidades dentro de la organización de cargos políticos y religiosos (en otras comunidades este término es sinónimo de "pasado"). En esta denominación genérica, los tzeltales de Bachajón distinguen diferentes autoridades. No presentaremos aquí más que aquellos que sobresalen en la jerarquía de cargos tradicionales designados con el nombre de muk'ul principal (gran principal) o ts'umbajon. Otro término que se refiere a la misma persona - $k$ 'atinab - aun cuando es empleado con menor frecuencia se conoce dentro de la literatura etnológica de las comunidades tzeltales de Chiapas (en particular Oxchuc, Siverts, 1969). Es necesario transcribir aquí la expresión propuesta por A. Beltrán de "Gobierno de k'atinabetik", para darle todo su sentido dentro del contexto regional, o de "Gobierno" de ts'umbajonetik" en la situación específica de Bachajón. Los empleamos indistintamente por considerarlos hoy equivalentes. 
realización de las ceremonias consisten sobre todo en alimentos, bebidas y pagos diversos; todo esto corresponde a sumas muy elevadas (de 1,000 a 2,000 pesos).

Para cada una de estas categorías de bajo nivel se reclutan dos capitanes: uno mayor o bankil y uno menor o ijts'in. Los capitanes son incorporados en su cargo durante la fiesta sobre la cual tienen la responsabilidad y terminarán en la misma ocasión al año siguiente. De esta manera, en el momento de cada una de las fiestas, el reparto de los cargos es:

$\begin{array}{lll}1 \text { Capitán } & \text { bankil } & \text { saliente } \\ 1 \text { Capitán } & \text { ijtsin } i n & \text { saliente } \\ 1 \text { Capitán } & \text { bankil } & \text { entrante } \\ 1 \text { Capitán } & \text { ijts'in } & \text { entrante }\end{array}$

Prácticamente, los gastos materiales de la fiesta son asumidos por los "salientes". Los "entrantes" tienen un año para ahorrar la cantidad necesaria para pagar la fiesta el día de su "salida" del sistema. Las fiestas duran tres días, para terminar el día preciso de la fiesta del Santo que corresponde festejar (el Carnaval tiene una duración de cinco días). El último día (durante el Carnaval el penúltimo, ver más adelante la cronología) tiene lugar el cambio de cargo de los salientes a los entrantes, bajo la forma de un "juramento" (en tzeltal: k'asesel k'op) que pronuncian los interesados en la casa de los capitanes salientes (esta ceremonia se realiza con mayor frecuencia, actualmente, dentro de la iglesia, en el transcurso de una misa que se celebra con este motivo).

Existe dentro de la misma categoría de capitán una jerarquía:

Capitanes de Santo (nivel 1)

Existen actualmente ocho cargos de este tipo, dedicados a cuatro santos titulares:

2 Capitanes:

San Sebastián:

San Miguel:

San Ignacio:

San Jerónimo:
1 bankil

Fiesta: 20 de enero

Fiesta: $\quad 8$ de mayo

Fiesta: $\quad 31$ de julio

Fiesta: $\quad 30$ de septiembre

En la participación dentro del Carnaval, sólo tienen un papel subsidiario: están presentes sólo como oficiales o miembros de la orga- 
nización religiosa. Llevan unos pañuelos alrededor del cuello y en el sombrero, sobre indumentaria de tipo europeo (camisa y pantalón).

\section{Capitanes de Carnaval (nivel 2)}

Éstos son cuatro cargos:

\section{Capitanes kajwaltik-Dios ("nuestro poderoso maestro}

\section{Dios"): un bankil, un ijts'in}

2 Capitanes juez o xiwes: un bankil, un ijts'in

En ellos recae la responsabilidad económica y ritual de las fiestas de Carnaval, pero no participan dentro de las fiestas de los santos. Van vestidos con trajes de lana roja (saco y pantalón) adornados con pequeños cascabeles; llevan también pañuelos alrededor del cuello y de la frente, y sombrero. Durante los ritos portan estandartes rojos.

En relación con los cargos de capitán, encontramos otros diferentes que no pertenecen al sistema jerárquico y que hemos llamado "personal de servicio". Para cada fiesta y para cada capitán son reclutados por los ts'umbajonetik dos a'abat ants (de $a^{\prime} b a t$ : servir y ants: mujer) o sirvientas, llamadas también con el nombre de yoksk'ab "los pies y las manos", así como una juy mats' (de juy: batir y mats: atole) que se consagran exclusivamente a la preparación de esta bebida, festiva por excelencia. Estas tres mujeres llevan en cierta manera la dirección de la cocina del capitán, en la cual también participan las mujeres de su patrilinaje y sus aliadas. Éste es un aspecto importante dentro del sistema, que es necesario subrayar aquí: las mujeres (esposas o parientes) del capitán, comparten el trabajo ( $\left.a^{\prime} t e l\right)$ y el status de éste, lo mismo que los hombres de su linaje. El cargo, definido como un trabajo, tiene un carácter netamente familiar (o casi siempre) tanto en lo que concierne a la participación económica, como a la acción ritual misma, por ejemplo: en el momento del Carnaval el traje de los capitanes kahwaltik-Dios y juez se lleva en forma rotativa por los hombres del grupo doméstico, o de la familia extendida, y todos participan, algunos en las correteadas, otros en las danzas, etc.

No podemos abandonar el tema de los cargos de los capitanes sin mencionar a los "musiqueros" (cuatro para cada capitán y para cada fiesta), quienes acompañan con tres guitarras y un violín todos los rituales de las danzas. El oficio de musiqueros no está limitado en tiempo, se trata de especialistas quienes alquilan sus servicios a los capitanes, y su actividad no entra dentro del sistema jerárquico. 
Caporal (nivel 3)

Éste es un cargo único, que se ejerce durante un periodo de siete años y cuyos ocupantes respectivos son elegidos también por los ts umbajonetik. Cuando su titular llega al término de su trabajo se le asigna un reemplazante que durante dos o tres años sigue con el aprendizaje necesario (en este caso, el caporal saliente es designado como bankil, y el postulante como ijts'in). El papel de caporal durante las fiestas consiste en dirigir los desplazamientos de los capitanes; es la persona que los presenta en los discursos rituales y quien los guía en sus acciones. El caporal debe también saber tocar la flauta ( $a m a y$ ) -un asistente llamado "oficial" lo acompaña con el tambor ( $\left.k^{\prime} a y o b\right)$. Esta música se distingue de la de los musiqueros en que ella marca todos los movimientos de los capitanes entre los diferentes lugares rituales (casa, casa verde, cruz, iglesia); los musiqueros no tocan sino bajo la ramada de la casa verde y algunas veces en la iglesia.

\section{Alguacil (nivel 4)}

Son los asistentes de los ts umbajonetik y los reemplazan eventualmente, siendo ellos los verdaderos maestros del ritual. Estos cargos se ocupan durante muchos años; para algunos constituyen una "escuela de $t s^{\prime} u m b a j o n$ " de la cual saldrán para llegar al último nivel dentro de la jerarquía. Los otros, aquellos que no han sido nombrados para suceder a los ts'umbajonetik, pueden conservar este cargo durante toda su vida, a menos de ser excluidos por quienes los han elegido.

\section{Ts'umbajon o k'atinab (nivel 5)}

Nos limitaremos, en este momento, a las definiciones mínimas de las diferentes funciones de los muk'ul principales (singular: $t s^{\prime} u m b a-$ jon; plural: ts'umbajonetik o k'atinabetik). (Un artículo que se encuentra en preparación, estará consagrado a las instancias de poder tradicional y desarrollará los elementos de este párrafo).

Los $k^{\prime}$ atinabetik son escogidos entre los poseedores de los cargos religiosos más importantes, pero no es aquí donde se limitan sus funciones, las cuales están íntimamente ligadas a la organización social donde se inscribe el sistema de cargos. Las diferentes expresiones empleadas por los tzeltales de Bachajón, que designan estas autoridades, nos van a ayudar a comprender mejor la importancia de estos hombres. 
A nivel de la explicación indígena, k'atinab y kalpul (o k'atinajibal) son una sola entidad: "Jate M. M., ay ta ho'wak lum, wayel winik" (“... y M. M., quien vive en ho'wak, es wayel winik"); a través de los papeles atribuidos al primero, recibimos en cierta medida una definición del segundo.

El término mismo de k'atinab se puede traducir por "aquél que recalienta" (de k'atinel: calentar, recalentar) y se refiere a la oposición calor/frío y al dualismo fundamental de la vida y de la muerte: "Si el kalpul no nos cuida, podemos estar tirados en cualquier parte, tener frío, humedad, nadie nos levanta y tenemos una enfermedad de frío".

En el mismo sentido, la noción de ti'way (literalmente "al borde del sueño"), otro nombre del k'atinab, expresa la permanencia del grupo y de su jefe que "vela" sobre sus hombres.

El muk'ul principal también tiene un papel activo, de protector y de curandero. Conoce y dirige los discursos rituales necesarios en todas las circunstancias, ya sea que se trate de las ceremonias para una casa nueva, la protección de las milpas tiernas, o en el momento de las grandes fiestas. Es a través de la palabra que el k'atinab garantiza a los miembros de su grupo la protección de sus ancestros, kananlum (los "guardianes de la tierra", los "guardianes del pueblo"), y del santo patrón de la comunidad, San Jerónimo o kajkanantik ("Nuestro señor guardián"). Por su intercesión la casa estará preservada de las enfermedades, las milpas sanas y productivas, y la fiesta cumplirá completamente su objetivo.

Como poxtawanej (curandero) es uno de los individuos que les proporciona protección y asistencia. Los curanderos son numerosos en la comunidad de Bachajón y particularmente en el barrio de San Sebastián, pero aunque no todos son k'atinabetik, éstos últimos son grandes curanderos, lo cual es una condición sine qua non del ejercicio de este cargo. La brujería ocupa un lugar muy importante dentro del arsenal de medios terapéuticos de que disponen; el ataque es frecuentemente la mejor defensa.

Sin embargo, el término de ts'umbajon, con el cual se le designa habitualmente, brinda la ilustración más rica de la importancia que se le da a este hombre, y por él al kalpul. La etimología de la palabra es compleja y muestra una interesante polisemia. Nos remite, por una parte, a ts'umbil (derivado de $t s^{\prime} u n e l$ ) que tiene el doble sentido de "sembrado" y de "suerte". Esta segunda acepción se utiliza en cuanto a la función de poxtawanej ("aquel que alivia", pero también "aquel que envía la enfermedad": ak'chamel). Más tarde discutiremos sobre la alusión al "sembrador". Por otra parte, la palabra ts'umbajon se 
deriva de ts'umbalinel, que significa "tener descendientes y ascendientes" (Slocum, 1971: 197). El término no designa aquí una simple función, sino un título, que se puede traducir por "ancestro viviente" y que justifica sus propias funciones. Se encuentra en la coyuntura del mundo de los vivientes (winiketik: "los hombres") y del mundo de los muertos (ch'ich' mametik: los ancestros; de ch'ich': sangre y mam: término clasificador para los hombres de la línea agnada; o meiltatiletik: "las madres y los padres"). Los vivientes a los cuales brindan protección y asistencia son los miembros - k'atinajib - de su kalpul.

Después de esta descripción "vertical" del sistema de cargos, veremos cómo éstos se articulan dentro de la organización social tradicional del barrio de San Sebastián.

Todos los cargos hasta aquí descritos se encuentran distribuidos entre los cuatro kalpules de acuerdo con dos modalidades:

- los cargos sometidos a rotación de un kalpul al otro

- los cargos fijos

Los cargos que se encuentran sometidos a rotación son aquéllos de capitanes (de Santo o de Carnaval) y el de caporal. Los primeros se ejercen cada año y se pasan de un kalpul al otro; los de caporal duran siete años. Los cargos que no se encuentran sometidos a rotación son los de alguacil y de ts'umbajon: cada kalpul posee en sí las diferentes autoridades quienes ejercen, como lo hemos visto, funciones que se encuentran más allá de las actividades ceremoniales colectivas.

La rotación de cargos se encuentra ligada a la disposición territorial de los cuatro kalpules en el perímetro del pueblo (Fig. 1). Siguiendo las manecillas del reloj, el orden del pasaje es lakma' (primogénito), $t i^{\prime} j a, b a^{\prime} i l$ y wayel. Para cada categoría de capitanes, el cargo menor (ijts'in, el menor) precede en la rotación al cargo mayor (bankil, el primogénito). ${ }^{6}$ (En la figura 2 ilustramos estos aspectos del Carnaval).

Señalemos que en la práctica estos cargos no son ocupados como deberían. Por una parte, el kalpul ba'il ya no participa en este sistema desde que las fiestas fueron modificadas por la prohibición del consumo de bebidas alcohólicas (al ts'umbajon lo consideran como un "haragán" porque no se ocupa del reclutamiento de los capitanes) y la rotación funciona efectivamente entre los tres grupos restantes.

6 Se puede aproximar este hecho al uso tzeltal de poner al principio los cargos menos importantes, por ejemplo dentro del orden de procesión. 
Por otra parte, los cargos de capitanes son los más costosos y los voluntarios los abandonan desde hace algunos años. Cuando un cargo no encuentra un representante dentro del kalpul correspondiente por la rotación, puede continuar su recorrido hacia otro kalpul; si ninguna persona se presenta para ocuparlo, regresará al primer kalpul o permanecerá vacante hasta el año siguiente.

Estos elementos, válidos para el conjunto de los cargos de capitanes, se precisan más adelante en el cuadro exclusivo del Carnaval.

\section{EL GARNAVAL}

El Carnaval en Bachajón, como en otras partes, es una fiesta móvil de acuerdo con la fiesta de Pascua. ${ }^{7}$ Originalmente cristiana, incluye también elementos indígenas. El sincretismo es tal que nos parece desprovisto de sentido establecer catálogos opuestos de elementos autóctonos y de rasgos importados. Incluido en la totalidad del ritual, cada elemento adquiere significado en relación con los otros, significado que puede ser en algunos casos opuesto a su sentido original: se verá, por ejemplo, lo que en esta fiesta simboliza la iglesia.

El Carnaval representa un drama antiguo - histórico y míticoy cada representación anual sirve a la reestructuración sociorreligiosa de la comunidad y a la renovación de la adaptación cultural de los actores tzeltales, en su tierra y en su historia. De este drama estudiaremos los personajes, las características de lugar y tiempo, en fin, su desarrollo.

Esquemáticamente, esta fiesta comprende algunos episodios repetidos y otros únicos. Entre los primeros y en orden de aparición tenemos:

El xoral: recorrido alrededor del pueblo con discursos rituales (pat'o'tan) en las cuatro esquinas de éste.

La guerra roja, ts'ajal guerra: simulación dramática en forma de una carrera, que completa el xoral, entre los salvajes ( $k^{\prime}$ abinales) y los responsables de cargo ( $\left.a^{\prime} t e l\right)$. El conjunto de ambos episodios se llama "caracol".

Las danzas (ahkot) entre muchachas y k'abinales y entre niñas y capitanes, que se llevan a cabo delante de las ramadas (yaxna: casas verdes) construidas por los capitanes jueces y kahwaltik-Dios, en donde se pasarán las responsabilidades del cargo.

7 1973: del 2 al 6 de marzo; 1974: del 22 al 26 de febrero; 1975: del 7 al 11 de febrero; 1977: del 18 al 22 de febrero. 
Entre los episodios únicos, citaremos:

La llegada de los k'abinales al claro, para encontrar a los responsables de cargo del pueblo e intercambiar los pat'o'tan.

El ritual de las pieles, que se efectúa en las yaxna con las mujeres.

El juramento o cambio de vara, que es el momento de cambio de cargo dentro de las yaxna concernientes.

\section{LOS ACTORES}

\section{Los espectadores}

Es necesario enfatizar el hecho de que la fiesta se efectúa para los espectadores, "aquellos que están reunidos y miran". En los diálogos ceremoniales que se realizan en los ritos del Carnaval, los verbos que indican éstas dos acciones están entre los más frecuentemente empleados: "mirar juntos" puede ser en tzeltal un verbo difirente de "mirar". El énfasis se pone constantemente en el hecho de que la fiesta manifiesta a los ojos de todos el cumplimiento de los ritos necesarios para la vida social. "Unidos y reunidos" (mololotik, sobolotik), llegando del pueblo y también de las rancherías, los espectadores se convierten en "testigos" y a partir de este momento ellos "sabrán", verbo que en tzeltal tiene como primer significado "recordar" ( $\left.n a^{\prime} e l\right)$.

\section{Los responsables de cargo}

La participación activa en los cargos se encuentra relacionada a la diferenciación económica, al mismo tiempo que, para algunos, al contexto de su propio linaje: "No todos pueden ocupar el cargo, porque no tienen maíz o frijol".

El sistema de cargos da un poder ${ }^{8}$ proporcional al nivel de la jerarquía a la cual pertenece, mientras que los gastos tienen una proporción inversa. Muchos criterios se combinan para dar a cada tipo de cargo una expresión particular. Por ejemplo:

8 Por el momento no definiremos este término. Aparecerá posteriormente en un artículo dedicado a "Los principales, su papel y su poder". Aquí indicamos solamente que se trata de una fuerza en el terreno socio-religioso, principalmente en la unión con los ancestros y los espíritus. 


\begin{tabular}{|c|c|c|c|c|}
\hline Cargo & Poder & Duración & Especificidad & Gasto \\
\hline Ts'umbajon & $\begin{array}{l}\text { máximo sobre } \\
\text { la comunidad }\end{array}$ & permanente & $\begin{array}{l}\text { responsable de } \\
\text { los rituales de } \\
\text { la comunidad }\end{array}$ & nulo \\
\hline Alguacil & $\begin{array}{l}\text { importante a } \\
\text { nivel ritual }\end{array}$ & Permanente $^{9}$ & $\begin{array}{l}\text { responsable de } \\
\text { ciertos rituales } \\
\text { reemplazando al } \\
\text { ts'umbajon }\end{array}$ & nulo \\
\hline Caporal & limitado & siete años & $\begin{array}{l}\text { responsable de } \\
\text { los rituales con- } \\
\text { cernientes a los } \\
\text { capitanes }\end{array}$ & nulo \\
\hline Capitanes & débil & anual & $\begin{array}{l}\text { responsable del } \\
\text { ritual de un } \\
\text { santo }\end{array}$ & máximo \\
\hline
\end{tabular}

\section{a) Capitanes del Carnaval}

Designados como los otros, esencialmente por razones de capacidad económica y de disposición personal, los capitanes que aseguran la carga del Carnaval son los capitanes kahwaltik-Dios - "nuestro gran maestro Dios"- y los capitanes jueces.

Los gastos necesarios consisten en:

Alimentos para las diferentes comidas: maíz, frijol, carne de puerco, panela; bebidas para las casas, las yaxna, las esquinas del xoral y la guerra roja consistentes en refrescos, aguamiel y "trago" de alcohol de caña; retribuciones para los familiares que han contribuido a la fiesta o a la construcción de la casa verde (yaxna), en el servicio de bebidas o en los gastos, ya sea en dinero o maíz, y para las mujeres que han colaborado en las actividades de la cocina, y una cantidad de dinero que se emplea para los músicos quienes son remunerados.

Los capitanes son considerados como "las manos y los pies" de la fiesta; ellos son los verdaderos actores, los responsables, aquellos que terminarán la fiesta agotados económica y físicamente. Son en efecto los capitanes salientes quienes en el momento del cambio de cargo pagan todo. Permanecen mudos, ya que no pronuncian ningún discurso, pero bailan delante de las casas verdes, recorren el xoral, son perseguidos durante la guerra roja y se incorporan en el momento propicio a los demás actores y a los participantes para beber. El capitán

${ }^{9}$ Hasta el momento en que se convierte en $t s^{\prime}$ umbajon. 
juez, el más importante de los dos, ofrece una comida final a los k'abinales el último día del Carnaval.

\section{b) El Caporal}

Su papel esencial dentro del Carnaval es guiar a los capitanes: al son de la flauta y acompañado de su oficial al tambor, él va a buscar a los capitanes a sus casas y los conduce por todos los lugares donde deben pasar: la iglesia, casas verdes, casas. El participa en los diálogos rituales con los músicos, los justicias y los principales (ya sean los ts'umbajonetik dentro del papel de "principal de yaxna" o los alguaciles).

\section{c) Alguaciles}

Los alguaciles, presentes durante el Carnaval, se distinguen por el grosor de su bastón; son esencialmente los interlocutores de los $k^{\prime} a b i$ nales desde de su llegada al claro; también son ellos quienes ofrecen a los k'abinales la comida o la bebida preparada por los capitanes, y finalmente dirigen las danzas de las niñas y corren con ellas en la guerra roja.

Hablaremos más tarde del ts'umbajon y de otros personajes del Carnaval, marcando el papel que se observa, ya sea de los actores, de los cuales hemos definido su status (alguacil por ejemplo), ya sea de otros cargos provisionales o definitivos de algunos actos. Introduciremos aquí los papeles de ilonk'op, de k'asesel k'op y de "principal de mesa", ya que hay quienes lo definen como un "tipo de alguaciles".

d) Ilonk'op: literalmente "quien ve la palabra"

El ilonk'op está encargado de "ver lo que se gasta y se come en la casa verde que construyó el capitán", por lo que se le llama "las manos del capitán". Es la persona que sirve los alimentos en la casa de las autoridades, se ocupa de los músicos y de las mujeres y jóvenes que han contribuido a la preparación de la comida del caporal. Él cuida de todo, desde arreglar los platos sobre la mesa hasta servir la comida cada vez que llega el momento de comer. Parece que le llaman también "principal de mesa". Se ocupa de recibir y acomodar a las personas en la casa verde, y pronuncia todos los diálogos rituales (pat'o'tan) de la mesa en la casa verde. Éste no corresponde al status de principal ts'umbajon, pero también recibe el nombre de "principal" en esta ocasión. Es elegido por consenso, debido a su facultad de responder en diálogos; el cargo dura toda su vida: "No se cambia. Es siempre igual". 


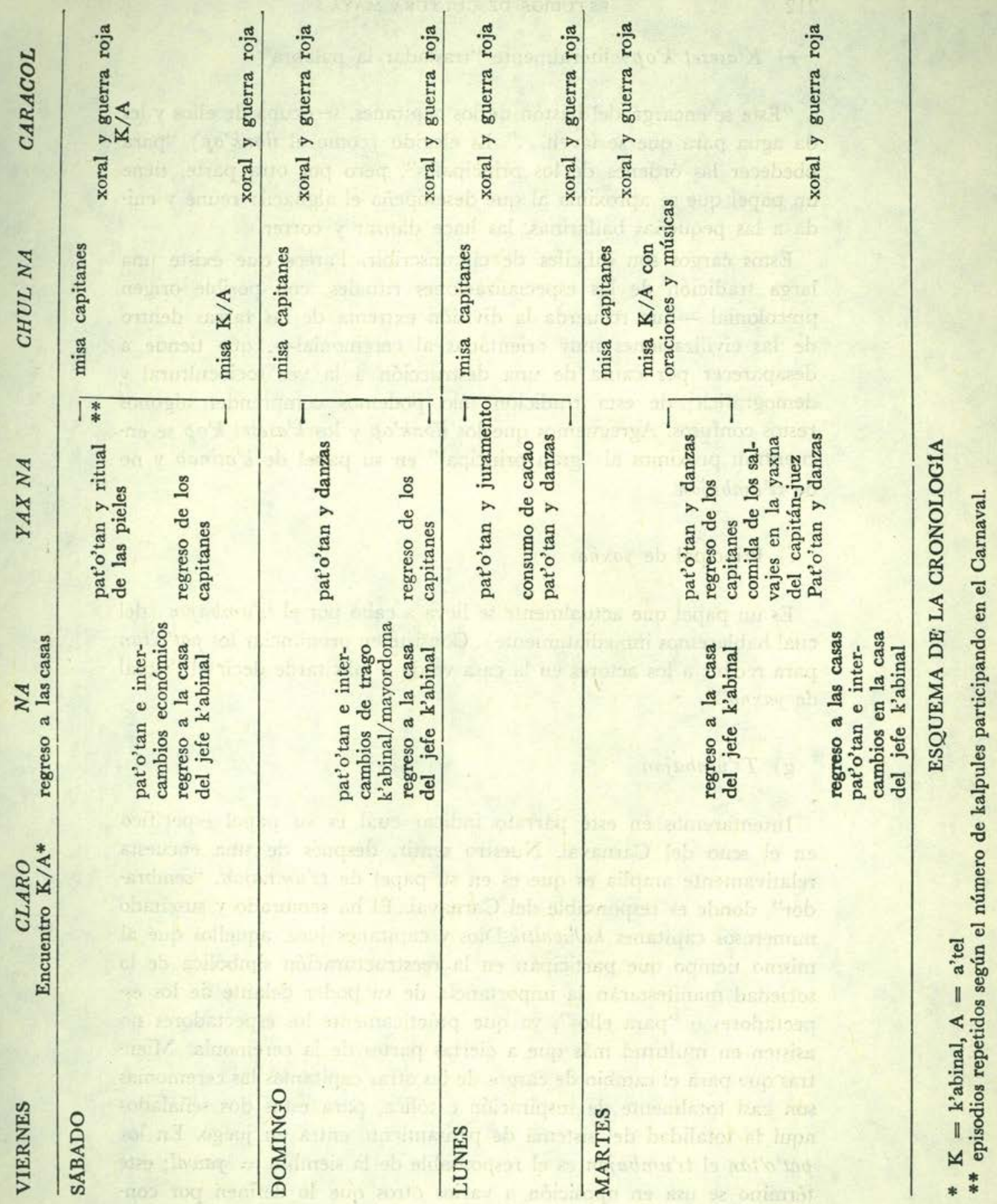


e) K'asesel k'op: literalmente "trasladar la palabra"

"Éste se encarga del bastón de los capitanes, se ocupa de ellos y les da agua para que se laven..." Es elegido (como el ilonk'op) "para obedecer las órdenes de los principales", pero por otra parte, tiene un papel que se aproxima al que desempeña el alguacil: reúne y cui$\mathrm{da}$ a las pequeñas bailarinas, las hace danzar y correr.

Estos cargos son difíciles de circunscribir. Parece que existe una larga tradición de las especializaciones rituales, con posible origen precolonial - que recuerda la división extrema de las tareas dentro de las civilizaciones muy orientadas al ceremonial-, que tiende a desaparecer por causa de una destrucción a la vez sociocultural y demográfica; de esta tradición sólo podemos comprender algunos restos confusos. Agreguemos que los ilonk'op y los k'asesel k'op se encuentran próximos al "gran principal" en su papel de k'atinab y no de $t$ 'sumbajon.

\section{f) Principal de yaxna}

Es un papel que actualmente se lleva a cabo por el ts'umbajon (del cual hablaremos inmediatamente). Consiste en pronunciar los pat'o'tan para recibir a los actores en la casa verde y más tarde decir el "ritual de yaxna".

\section{g) Tsumbajon}

Intentaremos en este párrafo indicar cuál es su papel específico en el seno del Carnaval. Nuestro sentir, después de una encuesta relativamente amplia es que es en su papel de ts'umbajon, "sembrador", donde es responsable del Carnaval. El ha sembrado y suscitado numerosos capitanes kahwaltik-Dios y capitanes juez, aquellos que al mismo tiempo que participan en la reestructuración simbólica de la sociedad manifestarán la importancia de su poder delante de los espectadores o "para ellos", ya que prácticamente los espectadores no asisten en multitud más que a ciertas partes de la ceremonia. Mientras que para el cambio de cargos de las otras capitanías las ceremonias son casi totalmente de inspiración católica, para estos dos señalados aquí la totalidad del sistema de pensamiento entra en juego. En los pat'o'tan el ts'umbajon es el responsable de la siembra = yawal; este término se usa en oposición a varios otros que lo definen por contraste: 
sikilna ("casa fría"): la relación con yawal señala que la semilla participa del calor de la vida y no del frío de la muerte o del abandono del hogar por el k'atinab (el que calienta);

ch'en ("cueva"): opuesto al "bosque" (wits), indica los lugares sagrados, pero unido a yawal, contribuye a la idea de la fecundidad que existe dentro de la semilla, por significar "agujero". Ch'enul = tebiniti ya spasbat xchenal y'uun ay bin ya sts'unot tey a: "Agujero: lo que nosotros hacemos para sembrar una planta".

Yawal se encuentra igualmente confrontado a "fuerza" (yu'el); "cuerpo" (bak'etal) y a otros conceptos que examinaremos en otra parte, pero que contribuyen todos a enriquecer esta noción de reproducción de la vida y de la sociedad. Es particularmente durante el Carnaval que el ts'umbajon al mismo tiempo que la idea de semilla, implica la de semilla humana, es decir, descendencia: como lo hemos visto arriba, $t s^{\prime} u m$ bal establece una relación entre los ancestros y sus descendientes (yuntikil).

De esta semilla del $t s^{\prime} u m b a j o n$ brota un cuerpo social, los hombres de su kalpul, cuyas manos y pies actúan para renovar los lazos entre los ancianos y los jóvenes, los muertos y los vivos, aquellos que protegen y quienes se encuentran en peligro.

El desarrollo del tiempo es un camino a recorrer, sin descanso y por actos idénticos a aquellos realizados por los ancestros. Vigilar esto es la tarea del ts'umbajon.

"M.M. es sembrador, él busca a los capitanes y les da su cargo. .." Sin las semillas nada podría transmitirse.

Durante el desarrollo del Carnaval, el ts'umbajon está siempre presente, asume el papel de principal de la casa verde, él dialoga con los $k$ 'abinales en el claro, en las casas, en las casas verdes y en las esquinas del xoral correspondientes al kalpul, del cual es la encarnación.

\section{h) La mayordoma}

Esposa del ts'umbajon, enseña y dirige a las muchachas escogidas por su marido, y participa en los diálogos con el jefe k'abinal en el momento de las danzas de las jóvenes. En el ritual de las pieles ella es una de las mujeres que reciben los regalos de la selva. 
i) Las jóvenes y las niñas bailarinas

Estas jóvenes y niñas son escogidas por el ts'umbajon para ser compañeras, las primeras de los $k^{\prime}$ abinales y las segundas de los capitanes, en el transcurso de las danzas. Ellas aseguran durante varios años seguidos los rituales, pero no preguntamos si esto no se debe sencillamente a la falta de candidatas a este papel, aunque los hechos no lo confirman. Se dice todavía que: "cada kalpul tiene sus propias bailarinas". La relación entre el kalpul y las niñas se conserva más.

\section{j) Los músicos}

Los músicos ofrecen un caso particular, debido a que ellos son contratados por los capitanes kahwaltik-Dios y juez y son pagados en dinero. Durante el Carnaval ellos no se mueven de la casa verde.

\section{k) Los justicias}

Otro caso particular son los justicias, representantes de cargos civiles, "se encargan de conseguir el ikits" (musgo de ocote) del cual se revestirán los k’abinales.

\section{Los k'abinales}

Ser k'abinal no es un "cargo" en sí. Se piensa que este nombre es la deformación de la palabra "karibes", denominación que se aplica a las tribus de las tierras bajas por los indios de las tierras altas, o que es el nombre de un jefe lacandón, K'ab-nal (Thompson, 1970: 29-30, Bricker, 1973:48).

En los diálogos rituales se les llama a'tine; "aquellos que sirven, aquellos que trabajan, aquellos que están encargados, porque ellos llevan todo". La etimología hipotética: a'batine ("servidor") no es conocida, pero todos los comentarios giran alrededor de la idea de "servicio". Este término de a'tine está siempre asociado con lum y k'apal, respectivamente: "territorio habitado" y "basura".

El grupo k'abinal está organizado de acuerdo a una jerarquía embrionaria de la siguiente manera:

- el jefe

- el k'abinal bank'il ("mayor") que toca la flauta 
- los llamados "mozos" (entre cinco y diez adultos o niños) que bailan y tocan otros instrumentos diferentes a la flauta.

Los miembros del grupo son nombrados permanentemente. Si se presenta una deserción, o si un k'abinal toma un cargo, éste es reemplazado.

El jefe nombra a su sucesor, principalmente dentro de los miembros de su familia. En el caso presente, el hijo mayor del jefe es $k$ 'abinal bank'il y su nieto de cinco años ya es k'abinal mozo.

Para la expedición en el bosque, ellos actúan como interlocutores de los $a^{3} t e l$, los portadores de cargo. Ellos les dan al mismo tiempo que los frutos de la selva, un lazo con los señores de la naturaleza, sin los cuales ellos no hubieran podido tocar a los animales y a los vegetales sin desencadenar la ira y las represalias (enfermedades y pérdida de las almas en particular).

A los señores de las cuevas, de la selva, de las cumbres, de las aguas de arriba y de las aguas de abajo se han dirigido los $k^{\prime}$ abinales para obtener los presentes que van a distribuir entre los poseedores de cargo del pueblo: animales de la montaña (xilul), palmas (mohtoyul), otras palmas (janatsul), mono (maxul), puerco (chitamul), saraguato (bats'ul), venado (chijul), faisán (jisul), perdiz (nacoul), etc.

La miel es igualmente un producto de intercambio propio de los k'abinales; está destinada, por una parte, a los capitanes a quienes les es dada por cada k'abinal, y por la otra sirve a los propios k'abinales para cubrirse el cuerpo y así pegarse el musgo de ocote del que se van a revestir a partir del domingo. A través de los diálogos y la miel actúan como mediadores entre el mundo salvaje y el mundo social. Son testigos del acto mismo del cambio de cargos durante el cual comparten con los a'tel los granos de cacao (ver infra: II, 1).

Los k'abinales participan también en el xoral, recorrido alrededor del pueblo en el cual las cuatro esquinas sirven de estaciones para decir los diálogos rituales. Aquí otra vez es secundario preguntarse lo que corresponde a la tradición cristiana o pagana dentro de este recorrido; pero es necesario insistir en el hecho de que lumal, el territorio que recorren en el xoral, está unido a lum, "la tierra habitada", la "tierra social", símbolo del mundo organizado y opuesto a balumilal, "mundo" en el sentido de la "totalidad del mundo", "tierras no socializadas" y por lo tanto "lugar peligroso" (cf. infra: III. 1.).

El xoral se termina con la tsajal guerra "la guerra roja", donde los capitanes, caporal y alguaciles son perseguidos por los k'abinales que buscan golpearlos con sus animales. 
Los k'abinales participan también de las danzas organizadas por los capitanes juez y los kahwaltik-Dios; su conducta es agresiva, más señaladamente en los pat'o'tan ("nosotros gritamos, atacamos, saltamos") que en sus gestos. Las bailarinas, sus compañeras en las danzas, son víctimas simbólicas de asaltos, ya que ellas se convierten en mujeres salvajes durante un instante, el espacio de una danza. Reciben sombrero y collares, y toman la pata de las pieles de los animales que les son ofrecidas en intercambio a la pareja.

Esta conducta agresiva de los k'abinales se encuentra continuamente presente durante los diálogos rituales y está marcada por gritos y alaridos. El viernes por la tarde tiene lugar un acto único en todo el Carnaval: en el momento en el que los k'abinales regresan del claro, a la mitad del camino se voltean hacia el pueblo, se detienen y lanzan en diferentes ocasiones largos gritos golpeándose la boca con la palma de la mano, haciendo como "gritos de animales de la selva, que no saben hablarles a sus dioses".

Observamos por lo tanto que los k'abinales, actores de las mismas escenas que los capitanes, caporales, alguaciles y principales, son característicamente opuestos.

El siguiente cuadro sintetiza estas oposiciones. (Véase cuadro pág. 217).

\section{Maruchas $y$ hombres blancos}

Algunas figuras muy populares del Carnaval, como las maruchas y los saktan (hombres blancos), tampoco son portadores de cargo, pero todo el aspecto de diversión dentro de la fiesta les incumbe. Empastados con cal, disfrazados como campesinos muy pobres o vestidos como mujeres, danzan, cantan, caricaturizan el desarrollo del Carnaval y de la vida diaria: días y noches ellos van parodiando tanto los discursos rituales como las peleas entre esposos.

\section{RITOS Y MITOS}

\section{Intercambios pacíficos}

a) Los pat'o'tan

El más importante de los intercambios pacíficos es el pat'o'tan: diálogo ritual, "saludo del corazón". Ésta es la actividad más intensa del Carnaval. Cada acto se abre y se cierra con pat'o'tan que se intercambian varias veces. En las casas verdes, en las esquinas del xoral, dentro de la iglesia, por todos los lugares del ritual se establecen estos 
$\mathrm{A}=a^{\prime} t e l:$ responsables de un cargo

$\mathrm{K}=k^{\prime}$ abinales: hombres salvajes

\begin{tabular}{|c|c|c|c|}
\hline $\begin{array}{l}\text { Definición: } \\
\text { FUNCION }\end{array}$ & PERSONA & JERARQUIA & PRESENCIA \\
\hline $\begin{array}{l}\text { A. los funcionarios } \\
\text { del cargo tienen } \\
\text { responsabilidad } \\
\text { de } a^{\prime} \text { tel }\end{array}$ & $\begin{array}{l}\text { después pasan } \\
\text { difícilmente a } \\
\text { k'abinal }\end{array}$ & $\begin{array}{l}\text { presencia de una } \\
\text { jerarquía a diver- } \\
\text { sos grados }\end{array}$ & $\begin{array}{l}\text { todas las } \\
\text { fiestas }\end{array}$ \\
\hline $\begin{array}{l}\text { K. Los k'abinales } \\
\text { no tienen cargo }\end{array}$ & $\begin{array}{l}\text { puede pasar en- } \\
\text { tre los a'tel }\end{array}$ & $\begin{array}{l}\text { jerarquía muy } \\
\text { reducida }\end{array}$ & $\begin{array}{l}\text { solamente en } \\
\text { el Carnaval }\end{array}$ \\
\hline $\begin{array}{l}\text { Atributos: } \\
\text { MUSICA* }\end{array}$ & VESTIDOS & \multicolumn{2}{|c|}{ ACCESORIOS } \\
\hline $\begin{array}{l}\text { A. violines y gui- } \\
\text { tarras** } \\
\text { K. Concha de tor- } \\
\text { tuga hajk*** } \\
\text { Caracol, puy }\end{array}$ & $\begin{array}{l}\text { tradicionales y } \\
\text { coloniales } \\
\text { ausencia, sólo el } \\
\text { pantalón }\end{array}$ & \multicolumn{2}{|c|}{$\begin{array}{l}\text { cintas, pañuelos, estandartes y } \\
\text { cascabeles } \\
\text { miel y musgo de ocote, pieles de ani- } \\
\text { males, collares de frutas y de "zacate" }\end{array}$} \\
\hline $\begin{array}{l}\text { Contexto: } \\
\text { FEMENINOS }\end{array}$ & REEMPLAZANTES & RAM & ADAS \\
\hline
\end{tabular}

A. Importante $\begin{aligned} & \text { principio de para los } a^{3} t e l \text { y los músicos } \\ & \text { reemplazo de } \\ & \text { cargos*\%*\% }\end{aligned}$

K. Casi nulo

los k'abinales no entran jamás, sólo el jefe (por su edad y por el sol)

Acciones:

SANTO

CARACOL

IGLESIA

SELVA

A. No corretean a a menudo y lar- espera en el pueblo k'abinales

go tiempo

$\mathrm{K}$. Corretean a los dos veces y por quince días a'tel

poco tiempo

\begin{tabular}{lll}
\hline RECORRIDOS & \multicolumn{1}{c}{ DANZAS } & \multicolumn{1}{c}{ MOVILIDAD } \\
\hline $\begin{array}{l}\text { A. Numerosos re- } \\
\text { corridos entre } \\
\text { las casas }\end{array}$ & $\begin{array}{l}\text { jamás en } \\
\text { línea recta } \\
\text { (excepción } \\
\text { tres bailarinas) }\end{array}$ & $\begin{array}{l}\text { entre cada acto de la fiesta perma- } \\
\text { necen en su lugar }\end{array}$ \\
$\begin{array}{l}\text { K. Recorrido úni- } \\
\text { jamás en } \\
\text { jefe la casa del }\end{array}$ & $\begin{array}{l}\text { círculo cada acto de la fiesta regresan } \\
\text { a la casa del jefe }\end{array}$ \\
\hline
\end{tabular}

* Poseen en común el tambor kayob y la flauta amay.

** Retribución a los músicos en pesos, ejecución en las yaxna.

*** Tocadas por los k'abinales mismos durante la marcha, rumbo a las cruces del xoral y al exterior de las yaxna.

**** Para reemplazar al principal: alguacil, un pariente puede ayudar o reemplazar a un hombre poseedor de un cargo, principalmente en el aspecto económico. 
diálogos. Es necesario insistir en el hecho de que tanto las oraciones como los diálogos rituales se pronuncian en todas las circunstancias de la vida diaria o ceremonial, en el momento en que se solicita una intervención de los espíritus; un hombre "que sabe hablar" y "responder" es un hombre que dispone de un gran poder, porque él es mediador en todas las cosas, entre lo sobrenatural y la vida de los hombres.

El rasgo más claro de los pat'o'tan es que nos hablan de una relación entre los "actores", los "responsables de cargo", y los "dioses". ${ }^{10}$ Por principio, los actores son los dioses en la ocasión de la fiesta: son su "cuerpo" y su "semilla", su "emanación", su "vida". En seguida, los actores rinden culto a los dioses: los "llevan", los "lavan", los "hacen vivir", los "manifiestan", los "perpetúan". Recíprocamente, los dioses protegen a los actores: los "cuidan", los "preservan", los "cubren" y "prolongan su vida". Esta relación necesaria, este "parentesco" de los dioses y los hombres, de los hombres y su tierra, se salvaguarda por la tradición: yokelal. Una parte de la tradición consiste, en efecto, en "decir los pat'o'tan", o sea, conservar este equilibrio sin el cual el hombre pierde su tierra y por lo tanto la vida, ya que todo alejamiento físico de su kalpul lo enferma, y muere, y aquello que lo une a su kalpul, es lo que lo une a sus ancestros por medio de los diálogos rituales. En la medida en que un hombre es fiel a la tradición, los espíritus (de sus ancestros) lo protegen, y él puede desde ese momento cumplir con una larga carrera de cargos al término de la cual será venerado y muchas veces alimentado. Al llegar a una edad avanzada, tendrá posibilidad de adquirir todas sus almas, es decir, un mayor conocimiento y un gran poder.

Un segundo rasgo que aparece claramente en los pat'o'tan es el énfasis puesto sobre la muchedumbre: "muchos" deben ver juntos el ritual de reiniciación y muchos son los que deben alegrarse. Es verdad que, para los tzeltales, la idea de proximidad -en el espacio o en el parentesco, conceptos que están ligados - es muy importante. Al estar unidos, están mejor protegidos y más felices. La alegría no es solitaria, es un hecho del grupo. "Estamos todos unidos para que todos estemos contentos"; es ésta la idea de fiesta que se aplica a la reunión. Cuando los músicos de los k'abinales, del caporal y de los capitanes tocan juntos "esto es muy alegre", dicen los tzeltales. Es una forma de cortesía que si se escucha música se encienda al mismo tiempo un radio de transistores para producir ruido. La iglesia no ha comprendido esto y por eso ha suprimido uno de los actos de la fiesta, durante el cual

10 En el sentido muy general de "espíritus sobrenaturales". 
las tres músicas hacían honor al canto del sacerdote tocando al mismo tiempo que él cantaba, para unirse en la fiesta.

Un último rasgo que es necesario subrayar, ya que aparece igualmente en el conjunto de los pat'o'tan, es la expresión de dolor, de la pena que se ha sufrido al encargarse de la fiesta. Se dice que los actores están acabados por el peso de las "contribuciones"; los pies agotados de haber caminado todos los caminos para buscar a los capitanes y para venir a la fiesta, las manos cansadas de haber trabajado en los campos para cosechar el maíz necesario para la fiesta, el corazón está huérfano y triste pues tiene el sentimiento de su pérdida, sin los espíritus; la boca está seca de haber pronunciado tantos discursos, la casa está fría porque se le ha abandonado para consagrarse exclusivamente a los "dioses". Ojalá que éstos lo recuerden, para proteger a los hombres que han sufrido por ellos...

\section{b) El trago}

Hay tres clases de trago actualmente: el alcohol de caña, el aguamiel $^{11}$ o miel fermentada y los refrescos.

El trago de alcohol, pox, se encuentra ligado al poder del principal: "el don de trago al principal incluye el donador dentro del kapul y lo integra como un miembro real". Cada petición al jefe del kalpul se acompaña de diversos dones, pero sobre todo de trago.

El trago está también relacionado con el poder de los dioses; intercambiado entre los actores del Carnaval, él representa la relación entre los hombres y los dioses, ya que los hombres son en ese momento preciso los dioses mismos, o una parte de los dioses que simbolizan el todo (manos, pies, ojos, etc...).

Existen, por otra parte, mitos de las Tierras Altas que dan como origen del trago la orina de Cristo. En fin, el trago representa a los a'tel y es frecuentemente ofrecido por ellos a los k'abinales.

El aguamiel, por lo contrario, es un producto que circula siempre a la inversa: de los k'abinales hacia los $a^{\prime} t e l$. Es un producto "natural" o "salvaje" que se ofrece en público y se consume en las casas verdes, al contrario del pox que se bebe siempre de inmediato donde es ofrecido.

Los refrescos se reparten y beben todo el tiempo, no tienen -en nuestro conocimiento- una connotación particular.

11 Por lo general el término "aguamiel" designa el jugo del maguey que, una vez fermentado, produce el pulque. Pero no tiene esta acepción en Chiapas. 
c) Los granos de cacao

Producto de tierra caliente por excelencia, parece que antiguamente los k'abinales traían el cacao de la selva, pero hoy los capitanes lo compran en el mercado ladino. Es distribuido a los responsables de cargo y a los $k$ 'abinales y consumido en el momento del "juramento". El cacao, es necesario recordarlo, fue un objeto de consumo ritual entre los mayas y tenía función de moneda en los Altos de Chiapas todavía al principio de este siglo. La Iglesia ha suprimido recientemente este rito, obligando a los capitanes a hacer el "juramento" dentro de la iglesia más bien que en las casas verdes; este cambio ha traído como consecuencia el suprimir la masticación de granos, probablemente considerada como incorrecta dentro de un lugar cristiano.

\section{d) Los productos de la selva}

Los habíamos señalado con anterioridad, cuando hablamos de los k'abinales. Algunos de estos productos se ofrecen crudos, otros cocidos:

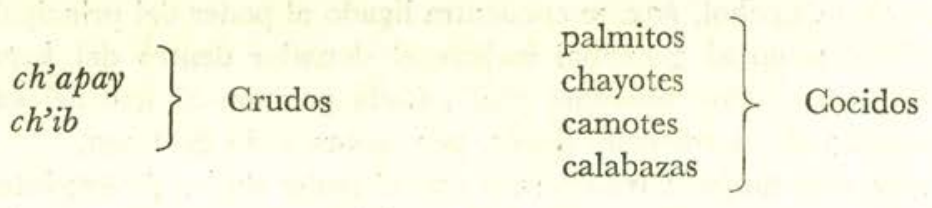

Entre los tzeltales, como entre los tzotziles, existe aún una relación entre la comida, el tiempo de las fiestas y los actos que se deben celebrar. Por ejemplo, cada día de la Semana Santa tiene una comida particular. "Los capitanes pasados tienen la costumbre de que en el día de la celebración vienen programadas las comidas que hacen..."

Después del Carnaval, los capitanes ofrecen igualmente una gran cantidad de alimentos a los k'abinales: frijoles, puerco, sal, masa, tortillas de frijol, trago, atole, pozole. En esta ocasión el trago es obsequiado por el jefe $k^{\prime}$ abinal.

\section{Intercambios guerreros}

a) El rito de la guerra roja (ts'ajal guerra)

La guerra roja forma parte de un ritual llamado "caracol" que se compone de dos partes: el xoral y la guerra roja. Respecto al xoral 
ya indicamos que se trata de un recorrido alrededor del pueblo, destacando las "cuatro esquinas" del xoral por medio de los pat'o'tan. Comienza frente a la iglesia y termina en la cancha donde se realizará la guerra roja. En ésta, los k'abinales, uno por uno, corren detrás de un capitán o de un alguacil con sus niñas bailarinas, agitando sus pieles de animales y tratando de golpear al fugitivo; esto se repite catorce veces. Intentaremos comparar esta correteada, uno de los actos más populares del Carnaval, con las variantes de un mito de oposición entre tzeltales y lacandones.

\section{b) El mito}

Disponemos en este momento de tres versiones del mito de la guerra roja. En el orden en que ellas han sido recogidas encontramos: un texto publicado por Slocum ${ }^{12}$ titulado: "Cómo el pueblo de Bachajón fue vencedor de los caribes"; un texto proveniente de Chilón, ${ }^{13}$ $\mathrm{y}$ un texto recogido por A. Breton en Bachajón. ${ }^{14}$

Transcribimos aquí una versión resumida de los tres textos a los cuales el lector podrá remitirse.

"Cómo el pueblo de Bachajón fue vencedor de los Caribes"

Características del texto: 8 páginas de texto en tzeltal, traducción yuxtalineal tzeltal-inglés. Resumen libre en inglés. Informante no precisado.

Los hombres de Bachajón eran ricos y numerosos. Por este motivo los caribes, celosos, vinieron a declararles la guerra, después de haberse reunido y preparado sus lanzas, arcos y flechas. Pero antes de llegar a Bachajón, se encontraron con los lab (espíritus protectores ancestrales) : una mujer anciana volando en un costal tejido muy flojo y un búho; pero ellos desperdiciaron todas sus flechas sin alcanzarlos. Los caribes siguieron caminando, pero como un pájaro había puesto su cola obstaculizando el paso del camino, de ésta manera ellos fueron marcados y contados cada vez que caminaban sobre él. El pájaro contó veinte veces cuatrocientos lacandones, y esto por siete veces consecutivas; lo anunció gritando a los de Bachajón. Constando que eran descubiertos, y como no tenían más flechas, los lacandones se retiraron. Éste fue el final de la primera expedición.

12 Slocum, 1965.

13 A. Becquelin-Monod y A. Breton, 1973: 101-105.

14 A. Breton, s.f., 58-59. 
Para la segunda expedición, idearon establecer negociaciones "para hablar de cosas convenientes y buenas". La gente de Bachajón los esperó deliberadamente con un banquete de atole de maíz dulce y de carne fresca; intercambiaron declaraciones amables y los caribes voraces se pusieron a comer. Como nunca habían probado estos platos, ellos se hartaron y no pudieron defenderse cuando los bachajontecos los vinieron a matar con bastones y piedras para moler. También un búho vino a levantarlos y a arrojarlos desde lo alto; así sus estómagos explotaron; los fugitivos fueron alcanzados y matados, a excepción de dos que penetraron en la tierra y salieron del otro lado de la colina reuniéndose con sus mujeres y los hombres restantes, y se fueron a vivir a las tierras bajas calientes.

"Noé y la guerra roja"

Características del texto: 5 páginas en tzetal, traducción yuxtalineal tzeltal-francés, traducción libre en francés. Informante: P. C. Chilón, bilingüe.

Noé y los suyos escaparon del diluvio construyendo una gran barca. Después, previendo un segundo diluvio, construyeron una gran torre, pero Dios se irritó con esta torre y separó las lenguas para dificultar a los trabajadores el laborar juntos. Los hombres se dividieron entonces en grupos y buscaron nuevos territorios. En particular, ciertos hijos de Noé fueron a vivir a la selva donde se convirtieron en monos. Los ancestros de los tzeltales, descendientes de Noé, hicieron la guerra a los hombres de la selva (jamal: "salvaje", opuesto a lum "aquéllos del pueblo"), los lacandones, los caribes, los monos, todos los animales, también descendientes de Noé. Primero los tzeltales fueron los vencedores, después lo fueron los lacandones. ${ }^{15}$

"La guerra de los caribes y los tzeltales"

Características del texto: 2 páginas, traducción francesa del español con los términos tzeltales. Informante: J. J.: Joy'be (Ranchería del barrio San Jerónimo, Bachajón), bilingüe. Según A. Breton, esta tradición presenta hechos históricos posiblemente anteriores a 1586, es decir, una de las incursiones lacandonas a los pueblos tzeltales cristianizados.

15 No corresponden a los lacandones yucatecos contemporáneos, sino a los chol-lacandones. 
En Joy'be, hubo una guerra entre los tzeltales y los caribes. Los tzeltales fueron vencedores debido a que supieron a tiempo que los lacandones se aproximaban, les salieron al encuentro y les invitaron a un banquete de carne de puerco. Durante el banquete, los lacandones fueron asesinados con hachas y manos de metate. Algunos lacandones alcanzaron a huir, pero los tzeltales, tal vez por temor a nuevas invasiones, emigraron a Bachajón, y bajo el auspicio de San Jerónimo construyeron el pueblo y su iglesia. Los caribes eliminados no volvieron nunca jamás a atacarlos.

Se destaca en estas tres versiones una guerra entre los tzeltales, hombres de la tierra socializada, y los lacandones, asimilados dentro de los animales salvajes. Su naturaleza simiesca resalta con el hecho de que la comida humana no les conviene. Atole y carne los adormece, los enferma y los vuelve incapaces de defenderse. En una de las versiones, ellos "explotan" literalmente por haber comido tanto. El hecho de que se hayan enfermado los coloca fuera de la normalidad. En fin, en lugar de la paz y la convivencia que representan la alegría de los tzeltales, nacen la división y la guerra entre los grupos. Los socializados desprecian muchísimo a los salvajes; éstos no solamente son considerados como animales, sino sobre todo se han transformado en tales debido a su obtuso entendimiento y su glotonería (versiones 1 y 3 ), o bien porque se han opuesto a la voluntad del Señor (versión 2). Aunque muy transformadas, estas variantes guardan una coloración esencialmente guerrera recordando un conflicto que consideramos como modelo de la guerra roja.

\section{Intercambios neutros o diversos}

Hay actos rituales en el Carnaval que pueden ser a veces pacíficos y a veces guerreros: las danzas, por ejemplo, entran tanto en una como en otra categorías, de acuerdo a si se trata de una danza entre personas portadoras de cargo o de danzas de oposición entre mujeres de cargo y k'abinales.

Se representan otros ritos a través de todo el Carnaval que no se pueden incluir en este esquema, pero que trataremos en el curso de la descripción cronológica. Si nosotros hemos elegido insistir sobre los polos: guerra/paz, no se debe a que éste sea el único eje de explicación posible, sino a que es el más importante.

Antes de abordar la cronología, propiamente dicha, daremos una apreciación del espacio en el cual se desarrolla ésta. 


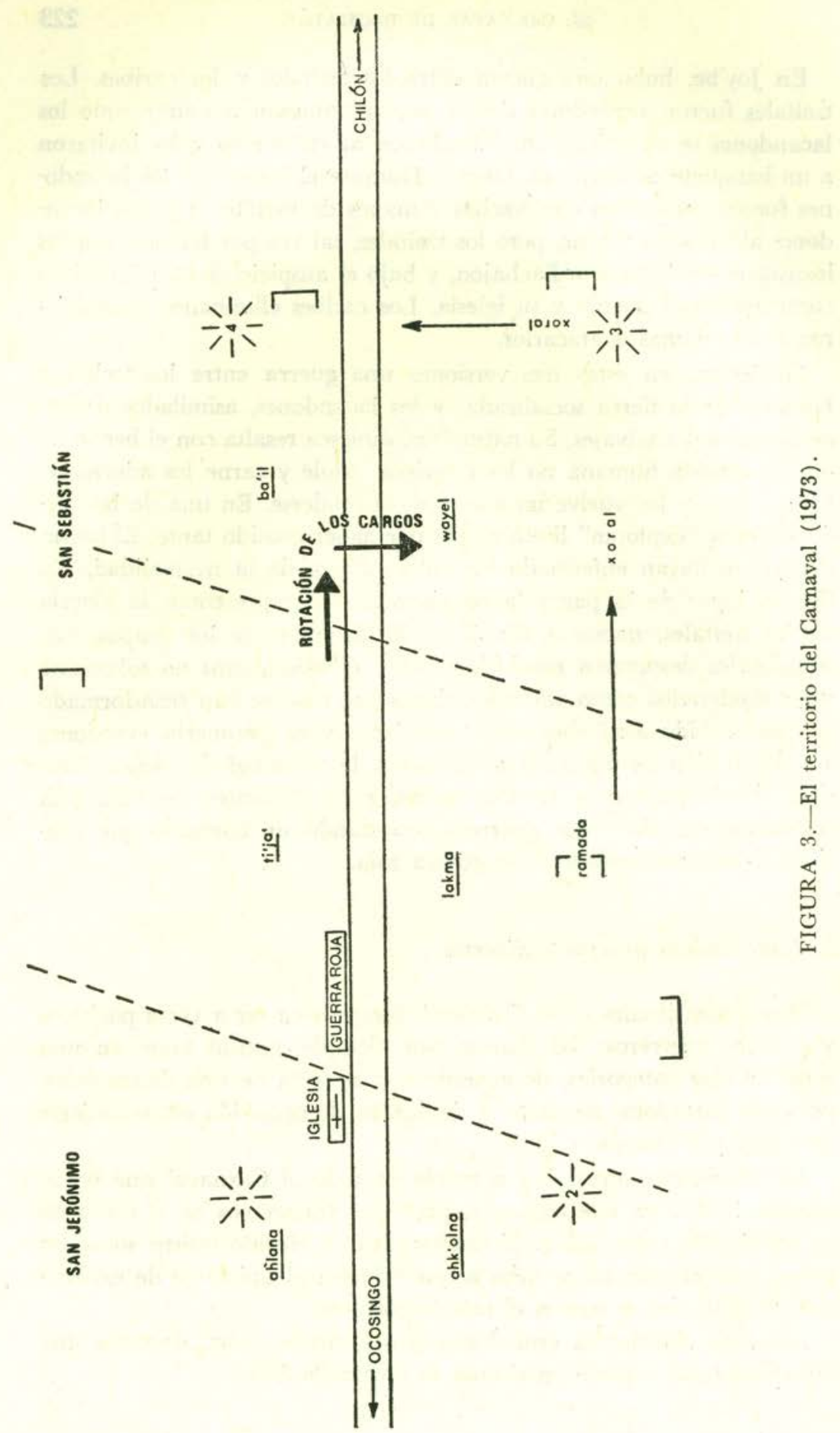

Estudios de Cultura Maya. Vol. XII, 1979

Instituto de Investigaciones Filológicas/

Centro de Estudios Mayas, UNAM

http://www.iifilologicas.unam.mx/estculmaya/ 


\section{LUGARES Y RECORRIDOS}

\section{Los lugares (Fig. 3)}

No podemos hablar de lugares determinados, o de recorridos, sin definir el mundo del Carnaval. Como hemos visto anteriormente, la fiesta es ubicada en el lum, el "territorio humano", el territorio socializado, el hombre tzeltal en relación con su tierra y su pueblo (cf. definición del kalpul). Lum se encuentra en oposición con las tierras calientes y selváticas de donde vienen los hombres no socializados, los $k^{\prime}$ abinales: sus límites son definidos en el recorrido del xoral alredededor del pueblo, que sigue, grosso modo, el vía crucis de la tradición cristiana. Estos extremos, donde se van a confrontar los a'tel y los k'abinales para sus diálogos, se llaman "las cuatro esquinas". Se sabe que el mundo maya se concebía con cuatro esquinas también: el pueblo simboliza entonces expresamente el mundo, es su imagen. Esta cosmología se apoya en los mismos términos empleados: la oposición más frecuentemente usada frente a lum es balumilal, "el mundo" en su totalidad, aquello que es exterior al lumal ("pueblo"), lo que es peligroso, frío, donde uno se encuentra solo, sin guardián; por consecuencia, en donde uno puede caer enfermo y morir. En su diccionario tzotzil, Laughlin (1973) señala como sentido de balamil: 1) "mundo", 2) "pérdida del alma" (esto significa "enfermedad" y "peligro de muerte"). Es, por tanto, en el interior del lum y del mundo representado por él, donde se va a desarrollar el Carnaval, con excepción del claro, lugar que pertenece a los dos espacios.

\section{a) El claro}

Corresponde a un espacio intermedio entre los dos mundo mencionados anteriormente, y del cual daremos más detalles al describir el ritual que se ejecuta.

\section{b) Las casas (na)}

Para la fiesta, las casas de todos los responsables de cargo están adornadas: el suelo está cubierto de agujas de pino y sobre los altares se encuentran dispuestas velas y flores. Muchos responsables de cargo no tienen una casa en el centro del pueblo, pero sus parientes o aliados les prestan la suya. Es dentro de las casas donde los k'abinales, al día siguiente de su llegada de la selva, ofrecen a las mujeres de los capitanes o a las parientes de los principales los regalos de la selva. 
En las casas se expresan los pat'o'tan de agredicimiento entre el jefe k'abinal y la mayordoma, después de los bailes. Se hacen también los pat'o'tan que señalan el intercambio de bebidas entre los dos grupos: a'tel / k'abinales.

c) Las ramadas (yaxna: casa verde)

Edificadas con motivo de la fiesta por los responsables de cargo, ayudados por sus parientes o aliados, las ramadas son construcciones sencillas de postes atados con mecates y techos de ramas y hojas; tres de los lados son tapados con petates.

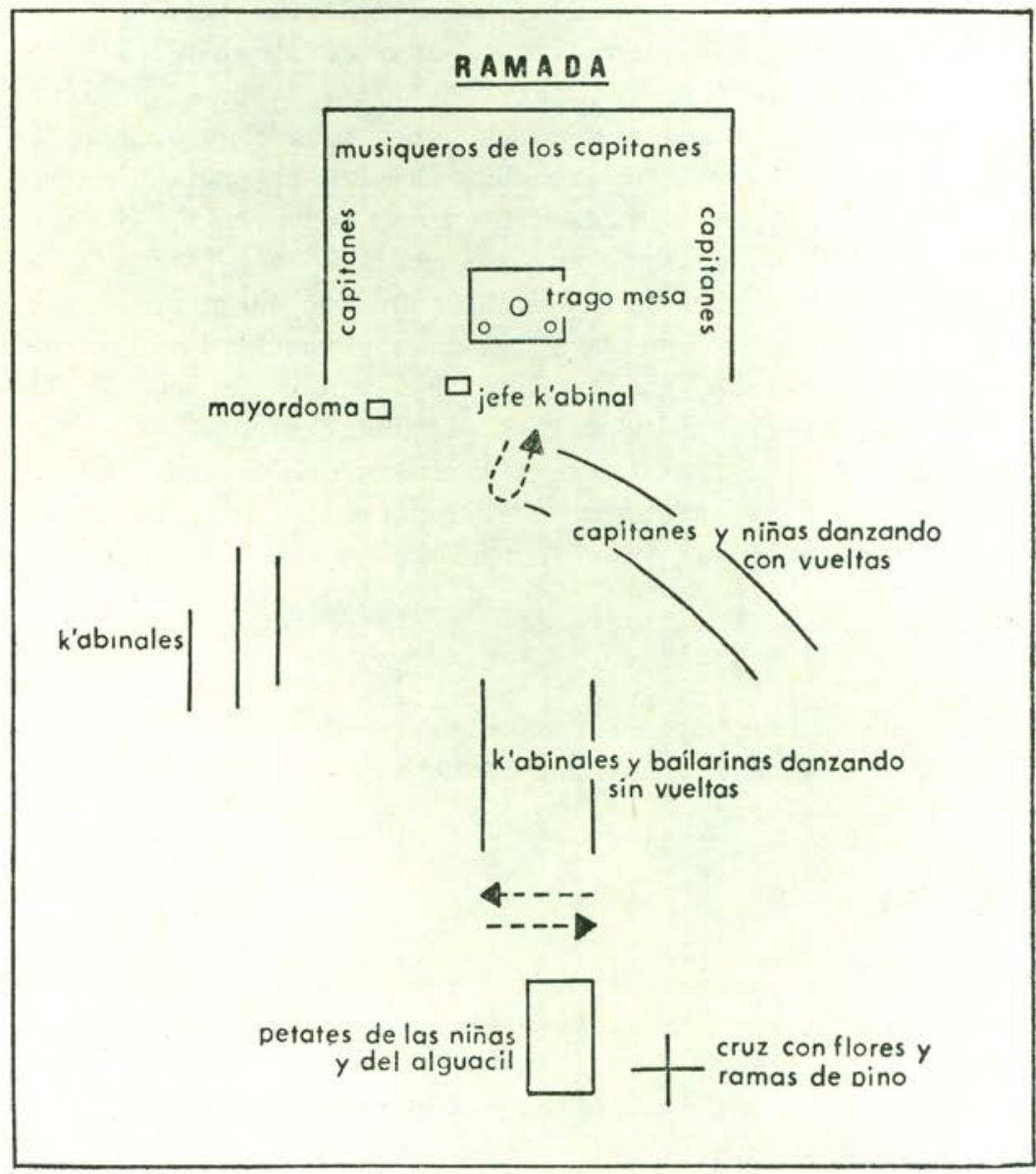

FIGURA 4.-Esquema de la yaxna

(una de las disposiciones de los actores) 
Las ramadas son ocupadas exclusivamente por los músicos y los capitanes, estos últimos se instalan sobre bancos perpendiculares a la entrada y los primeros en bancos al fondo. Los k'abinales permanecen siempre en el exterior. Las ramadas, así como los cargos del Carnaval, están ligadas al kalpul, puesto que se construyen en el kalpul al que pertenece el responsable de cargo.

En las yaxna se realizan los rituales de las pieles y las danzas, así como también el juramento: se intercambian los productos de la selva, el trago, los granos de cacao y los pat'o'tan. Éste es el lugar ritual por excelencia, ligado específicamente a los capitanes kahwaltik-Dios y juez, entrantes y salientes, quienes pasan la mayor parte del tiempo esperando a los k'abinales y participando en los diferentes acontecimientos del ritual.

\section{d) La iglesia (ch'ulna)}

La iglesia es frecuentada particularmente por las capitanes quienes asisten a la misa todos los días, mañana y tarde. Los k'abinales no vienen más que en dos ocasiones y muy brevemente. El atrio marca el inicio del $x o r a l$. La separación es muy clara entre los $a^{\prime} t e l$, mundo interior y cristianizado, y los k'abinales, mundo exterior y pagano, aquél de la sátira y la inversión.

Es interesante señalar que la Iglesia fortalece una división estructural esencial dentro del Carnaval; a pesar de una aparente importancia, la Iglesia y su simbolismo se mantienen fuera de la esencia del Carnaval y, lejos de imponer su visión cristiana, se pliegan a las tradiciones. Sin embargo, este equilibrio precario está en vías de destruirse, y una evolución viene apareciendo desde hace algunos años, de la cual hablaremos más adelante. De hecho, los padres no solamente exigen una participación formal, quieren también una participación espiritual, garantía de una renuncia progresiva de sus antiguas tradiciones.

\section{El recorrido}

Sería incompleto hablar de espacio mencionando únicamente lugares de acciones estáticas. El Carnaval es una fiesta de recorrido, de movimientos, de ritmos.

\section{a) El ritmo k'abinal}

Los k'abinales son esencialmente "móviles"; después de cada uno de los actos de la fiesta regresan a la casa del jefe: entre las danzas, 
entre los rituales de las pieles, entre las visistas a las casas, ellos vuelven a su propio centro; en esto son muy diferentes a los responsables de cargo. De esta casa salen tocando los instrumentos musicales y regresan de la misma manera. En el transcurso de las danzas, se caracterizan por sus pasos (hacia adelante y hacia atrás sin voltear jamás) que los diferencian otra vez de los a'tel.

\section{b) El ritmo a'tel}

En cuanto a los capitanes, ellos son esencialmente "estables", permanecen en las yaxna, de las cuales se responsabilizan durante todo el día, a excepción de cuando deben ir a la iglesia o participar en un caracol. Esperan a los k'abinales mientras que sus parientes se apresuran entre las casas y las yaxna. En sus danzas, los capitanes se oponen a los k'abinales dando media vuelta cada tres pasos, así como sus compañeras, las niñas. Las bailarinas de mayor edad están acaparadas por los salvajes y danzan como ellos en línea recta.

\section{c) El caracol (anumal)}

Se compone, como se indicó anteriormente, de dos partes: el xoral (que proviene de solar?) y la guerra roja.

La palabra joy, empleada en los pat'o'tan, que se traduce por "circular" en los léxicos, y que se aplica al xoral, describe una situación de recorrido por las cuatro esquinas. Al explicar la palabra xoral, dicen los actores que se define corno "cuatro lugares de estación". Entonces, el xoral es concebido más cuadrangular que redondo dentro del pensamiento indígena, y parece coincidir con una visión precristiana de la construcción del mundo.

El recorrido a las cuatro esquinas se hace corriendo rápidamente con las banderas flotando en el aire; los lugares donde se pronuncian los pat'o'tan corresponden a los kalpules de los responsables de la fiesta y se señalan con una cruz frente a la cual se detienen. Después de continuos pat'o'tan, agradecimientos y bebidas, los grupos k'abinal y a'tel continúan su carrera hasta llegar al lugar de la guerra roja. El xoral es un recorrido serio y sin espectadores, mientras que la guerra roja es una carrera cómica para la cual pueden llegar centenares de personas.

\section{d) La guerra roja}

A su turno, los capitanes y los alguaciles, acompañados de las niñas, salen corriendo alrededor del terreno, perseguidos por los $k^{\prime}$ abinales, quienes buscan golpearlos agitando sus pieles en el aire. 


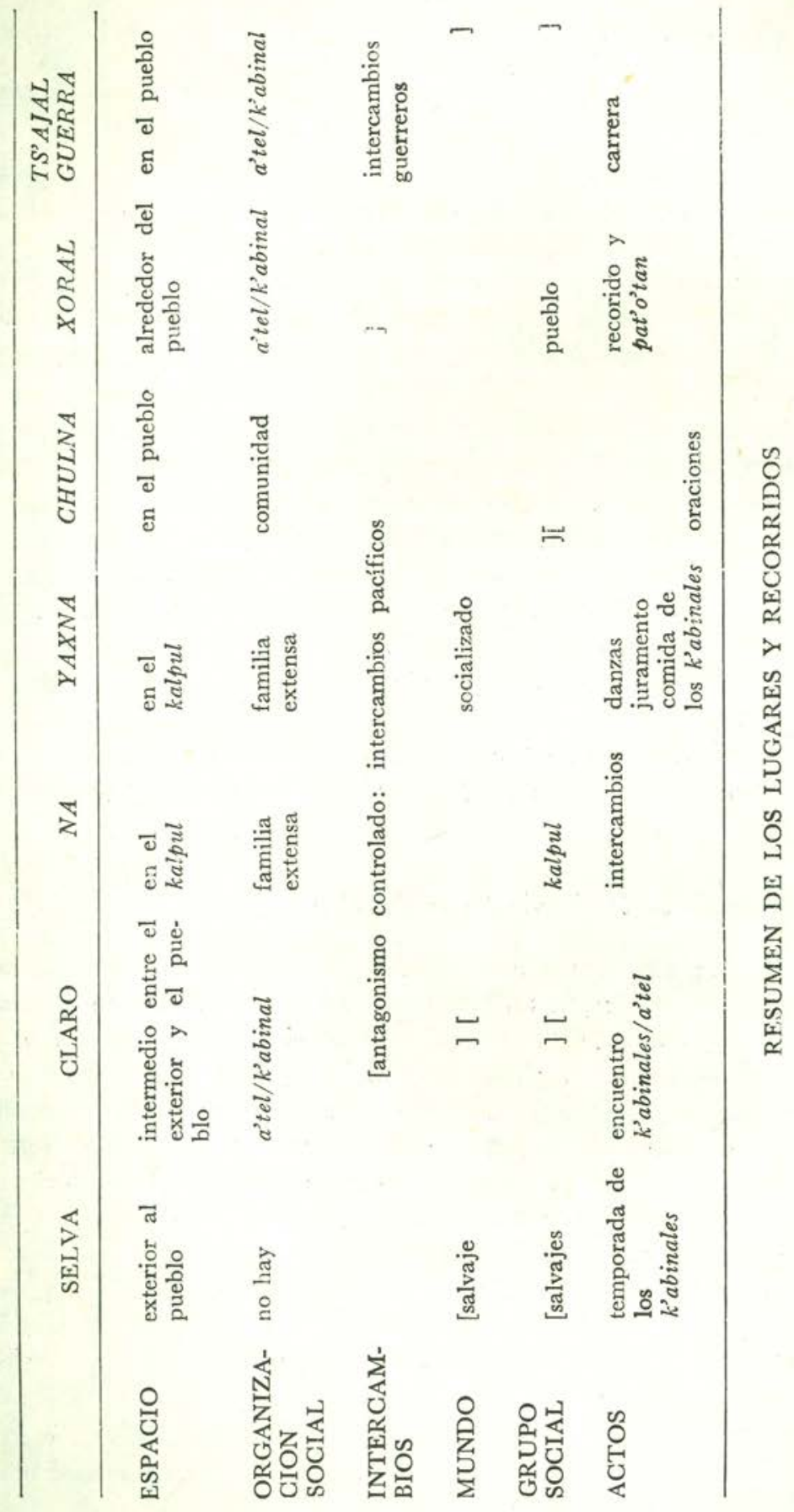

Estudios de Cultura Maya. Vol. XII, 1979

Instituto de Investigaciones Filológicas/

Centro de Estudios Mayas, UNAM

http://www.iifilologicas.unam.mx/estculmaya/ 


\section{CRONOLOGÍA}

\section{Preparativos}

Recorriendo su kalpul, los ts'umbajonetik invitan a los nuevos hombres que van a entrar en el cargo de capitán kahwaltik-Dios y en el de capitán juez. Por el conocimiento tan perfecto que tienen del territorio, de los hombres, de los recursos económicos y espirituales de cada uno, los tsumbajonetik los escogen, y por medio de discursos formales y conversaciones informales, intentan convencerlos para que acepten el cargo.

Al final de la fiesta de San Sebastián, los oficiales de los kalpules patrocinadores del Carnaval (para el cual han aceptado recibir los cargos) visitan a los $k^{\prime}$ abinales reunidos para esta ocasión. Les ofrecen tortillas, dulces de frutas, atole y trago. Las fechas de partida a la selva y el regreso se fijan de común acuerdo. El jefe $k^{\prime} a b i n a l$ se reúne con sus compañeros ya que: "si no hay k'abinal no hay fiesta". La víspera de la salida a la selva, los k'abinales se presentan a la iglesia, al mismo tiempo que los ts'umbajonetik, para escuchar la misa y ofrecer unas velas.

Los preparativos de los $t s^{\prime} u m b a j o n e t i k$ pueden ser concebidos como largos e incluyen el recorrido de un territorio altamente socializado, el kalpul.

\section{Temporada de los k'abinales en la selva}

Se trata de una incursión de quince días en tierra caliente. La colonia a la cual se dirigen los $k^{\prime}$ abinales se llama axuk'pa y se localiza cerca del río Tulijá. Matan animales de la selva (jamal chambalametik) y regresan con las pieles, la carne y algunas plantas variadas. Esta expedición es - según sabemos- única en las tierras altas de Chiapas. No hemos encontrado a este respecto más que dos alusiones en los textos: una de Gossen, que hace referencia a un discurso ritual pronunciado por los chamulas en el momento de contratar a los colectores de leña 'para el Carnaval: "nosotros esperaremos en la selva..." (Gossen, 1974: 178-179) ; la otra se encuentra en Nash, y ahí se trata de una tradición ya abandonada que se refiere a: "las comidas en común de calabazas provenientes de las tierras calientes" durante el Carnaval (Nash, 1970: 224).

Haciendo contraste con los preparativos de los t'umbajonetik, los preparativos de los $k^{\prime}$ abinales son breves (15 días) y consisten en una incursión hacia las tierras calientes. 


\section{Viernes: El encuentro en el claro}

El claro donde se reúnen los k'abinales y los a'tel, aproximadamente a $2 \mathrm{~km}$. de Bachajón sobre la vertiente de la colina, es un espacio intermedio entre la selva y el pueblo. Corresponde al escenario del evento más importante para los etnólogos.

Desde muy lejos se escuchan las conchas de los hombres salvajes que se acercan. En el momento en que aparecen, vestidos de harapos, cargados de pieles y costales llenos de vegetales, y tocando música, forman un gran contraste con los $a^{\prime}$ tel vestidos de blanco y silenciosos que los esperan desde principios de la tarde. Tiran sus cosas al suelo y se arrojan sobre los responsables de cargo: ts'umbajonetik, alguaciles, caporal, capitanes kahwaltik-Dios y juez salientes. Los cargan de pieles colocándolas sobre su cabeza y sobre sus espaldas. El jefe $k^{\prime} a b i$ nal y el ts'umbajon comienzan largas letanías a dos voces que van a continuar incesantemente durante todo el Carnaval, los pat'o'tan, acompañados de la música de los k'abinales, de gritos y silbidos. Después de haber teminado los pat'o'tan, los k'abinales reciben de los responsables de cargo trago y cigarros, y ellos les ofrecen el aguamiel.

El regreso del claro se efectúa por dos caminos diferentes: los "oficiales" regresan directamente; en cambio los k'abinales toman otro camino y se detienen en muchos cementerios. ${ }^{16}$ Mientras que el jefe hace una corta invocación, se toca la música; después, los k'abinales reunidos gritan y se dan palmadas en la boca; por fin, dan un fuerte grito y silban; lo hacen cada vez que se detienen. Desde el pueblo de Bachajón, los gritos parecen venir de todas partes, de todas direcciones y uno siente una gran impresión de encerramiento.

El claro es un lugar de encuentro, exterior al pueblo, donde entre los actores - fácilmente identificables - se lleva a cabo un rito de mediación entre guerra y paz, pueblo y selva, civilizados y salvajes, en fin, entre naturaleza y cultura.

\section{Sábado: el ritual de las pieles}

Mientras se terminan los últimos preparativos de la yaxna (la ramada), se almacena la leña necesaria para la cocina y los alimentos. Los capitanes se encuentran en misa, luego esperan en el atrio de la iglesia la llegada de los k'abinales (quienes han pintado sus sombreros de verde y pegado una cruz de paja en él), para que al encontrarse hagan juntos un xoral y una guerra roja.

16 En 1977, los nombres de los cementerios correspondían a: Estancia, golomil, baxk'ayowil, tsosts stahluk'ub. 
En la primera yaxna que los k'abinales van a visitar, las mujeres del ts'umbajon, esposa o hijas, y las del capitán de esta yaxna, están cargadas de costales con regalos de la selva, preparados en la casa del jefe $k^{\prime}$ abinal (les dan también canastas, situadas sobre la mesa); se colocan las pieles de animal arriba del mecapal, y encima los sombreros de los k'abinales. Los diálogos rituales se hacen entre el jefe $k^{\prime} a b i n a l$ y el $t s^{\prime} u m b a j o n$ y/o los alguaciles del kalpul. Después de los pat'o'tan, los actores entran en la casa, descansan e inician nuevamente los diálogos. En las canastas, las mujeres sustituyen los presentes que han recibido por botellas de aguardiente que los k'abinales beben y ofrecen a los asistentes. Este ritual se repite en todos los $\mathrm{kal}$ pules donde se hace la fiesta.

Entre los discursos en las casas, el caporal y su oficial tocan la flauta y el tambor. Durante los diálogos se escucha solamente el tambor.

Al final de la tarde, después de haber pasado por todas las casas de los responsables, los $k^{\prime}$ abinales se reúnen delante de la iglesia con los capitanes que les esperan con una vela en la mano. Todos entran y oran juntos mientras que tocan las dos músicas, k'abinal / caporal. El jefe k'abinal da la orden de terminar el acto y todos salen para llevar a cabo un caracol que concluirá la jornada.

\section{Domingo: el día de las danzas}

Los k'abinales se han revestido con el musgo del ocote, pegado sobre la miel que se han untado. Los capitanes y las bailarinas se han vestido con trajes de tipo colonial (trajes rojos para los hombres y vestidos floreados para las jovencitas, peinadas con trenzas y listones de colores).

Después de la misa para los capitanes y el caracol, en común con los k'abinales, la fiesta se desarrolla en las yaxna de los capitanes, exclusivamente, con la introducción de nuevos personajes: los músicos (tres guitarristas y un violinista) que no van a dejar de tocar ni un momento. Al llegar los ts'umbajonetik, tocan la música del capitán y la música del caporal. Se pronuncian unos diálogos debido a que el ts'umbajon está en funciones de "principal de yaxna": saluda a los músicos, al caporal y a su oficial; el jefe de los músicos, así como el caporal, le responden. Llega entonces su ayudante principal, el principal de mesa, que se va a encargar de cuidar durante todo el día del buen orden de las cosas y de las personas.

Cuando llegan los k'abinales los tres músicos tocan juntos; "es la gran alegría". Todos se saludan y en ese momento llegan las jóvenes danzantes quienes serán las parejas de los k'abinales, y las niñas quie- 
nes acompañarán a los capitanes. La mayordoma les conduce a la casa después de cada baile. Siempre hay tres danzas en serie. Los diálogos que se intercambian entre la mayordoma y el jefe $k^{\prime} a b i n a l$ se efectúan ya sea durante las danzas o al finalizar, en la casa donde se intercambia el trago. La mayordoma no toma trago pero lo lleva en una ollita tras ella. Las jóvenes permanecen junto a la pared con la cabeza inclinada en una actitud ostensiblemente austera; esta actitud es conservada durante las danzas, y sus faldas largas que arrastran por el suelo contribuyen a la rigidez de sus movimientos. El jefe k'abinal inicia y termina cada danza y presiona mucho a los capitanes, extenuados de cansancio y calor, a continuar bailando.

\section{Lunes: El cambio de vara o "juramento"}

En las ramadas se desarrolla un ritual llamado "juramento", practicado junto con los responsables de cargo salientes.

Después del caracol, los k'abinales se presentan a la primera yaxna. Sobre la mesa están colocados dos bastones de alguacil, dos cruces y dos velas. Delante, sobre los petates dispuestos especialmente para esta ocasión, los hombres y las mujeres "concernientes" en este cambio rezan, después besan el suelo y se adelantan un poco de rodillas. Vuelven a rezar, se postran y se adelantan; esto se repite tres veces. Cuando han llegado al altar, se levantan, besan la cruz, toman las banderas y se retiran. Durante todo ese tiempo los k'abinales silban, gritan y aullan.

$\mathrm{Al}$ acabar con esta parte de la ceremonia, el jefe k'abinal saluda y besa la cruz lo mismo que sus gentes; después de una corta oración dicha por el k'abinal se saludan según su función: los más importantes imponen el revés de su mano sobre la frente del menos importante, quien se postra ante él.

Después de haber compartido el trago, se reparten los granos de cacao entre todos, k'abinales y a'tel, y todos los consumen. Esta cere-

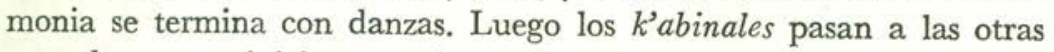
ramadas para reiniciar otros juramentos. El día se termina como todos los demás con un "santo caracol".

\section{Martes: La comida de los salvajes}

Después del caracol matinal se reúnen los a'tel y los k'abinales dentro de la iglesia, donde se lleva a cabo al mismo tiempo la comunión de los niños del pueblo. Cuando cantan, ya sea el sacerdote o la asamblea, resuenan las músicas del Carnaval. Debemos decir "resona- 
ban" ya que ahora la iglesia ha prohibido este sincretismo musical sorprendente que manifestaba entre los tzeltales la alegría y la unión. $\mathrm{El}$ jefe k'abinal, los ts'umbajonetik y los capitanes rezan un rato. Al principio de la tarde, después de un caracol y una nueva serie de danzas, el capitán saliente ofrece una comida a los k'abinales.

Con una simple ablusión de manos y sin ningún discurso, los capitanes juez, los alguaciles del kapul y dos ayudantes sirven caldo, tortillas, un guisado de carne de puerco y frijoles negros, sal y atole de maíz que reparte el jefe k'abinal entre sus hombnes. Las pieles de animales y los instrumentos musicales están tendidos aparte sobre una mesa; tienen canastas de granos de maíz cuyo contenido será arrojado más tarde, salvo que exista un permiso especial del jefe $k^{\prime} a b i n a l$ para no perderlo. Encontramos aquí una clara asimilación entre los animales salvajes y los instrumentos: "el tambor es animal", dicen; y por esta identificación, los salvajes (hombres y animales) se civilizan.

La tarde transcurre con danzas en las ramadas, un último xoral y una última guerra roja marcan el final del Carnaval "público". En la noche, una última y privada ceremonia se lleva a cabo; en ella los capitanes de los kalpules representados llevan a los k'abinales costales llenos de calabazas, puerco, frijol, masa, tortillas, pozole, atole y aguardiente. Se intercambian largos pat'o'tan y se comparte el trago, repartido por el jefe k'abinal. Después todos se van y se termina la fiesta. Se puede pensar entonces en el próximo Carnaval (cf. Esquema de la Cronología).

\section{CONCLUSIONES}

\section{Nota histórica}

Conocemos sólo algunos puntos en lo que toca al papel de los $k^{\prime} a b i$ nales o "caribes" o "lacandones" en la historia de Bachajón.

Bachajón fue fundada por el dominico Pedro Lorenzo probablemente después de 1560, fecha de su llegada a Chiapas, y antes de 1577, fecha de su muerte en Palenque (Ximénez, 1929: 31-41, 149, $152)$. Él reagrupó a los indígenas que vivían en las montañas situadas al este de Ocosingo (Ibid: II, 204, 252) y quienes eran vecinos inmediatos de los chol-lacandones. Los indios de Bachajón sirvieron de guía a los españoles en sus expediciones de 1586 (Ibid: II, 204) y de 1696 (Ibid: III, 40) contra los chol-lacandones, acusados de atacar a los pueblos cristianizados. Para la última expedición (1696), se cita a Gaspar de Miranda, indio de Bachajón, como guía principal, y Ximé- 
nez precisa que las gentes de Bachajón conocían las montañas hasta el lago de los lacandones (Thompson, 1970: 28, carta 2, identificando este lago con la laguna de Miramar).

En el momento de la expedición de 1695-96 se creía que los lacandones se encontraban próximos a Ocosingo (Villagutierre y Sotomayor, 1933: 178-179). Para Ximénez (1929, 31: III, 12), éstos se encontraban sumamente lejos y los indios de Ocosingo fingían terror para no tener que preparar el campamento de los soldados, al noreste del pueblo. Después de la llegada a Ocosingo en 1564 de los lacandones de Pochutla, evangelizados por Pedro Lorenzo, y de la "entrada" efectuada en 1586, los otros lacandones no sometidos, se instalaron en el sureste de la Laguna Miramar a unos $150 \mathrm{~km}$. de Ocosingo (Thompson, 1970: 27-29) donde la "entrada" de 1696 llegó a someterlos.

Ximénez señala, al principio del siglo xvIIr, que los indios cristianizados continuaban pretendiendo que eran atacados por los lacandones. Dice saber por propia investigación "... que las voces de que los Lacandones entraban el Jueves Santo en el pueblo de Ocosingo y en otros de los Zendales eran vagas y sin fundamento". Indica los detalles siguientes con relación a la actitud de los indígenas ante la simulación de la llegada de los lacandones:

En el pueblo de Ocosingo, era cosa ya sabida que todos los años el Jueves Santo en la noche se alborotaban y se recogían á la Yglesia diciendo que venían Lacandones y que andaban ya dentro del pueblo, y aunque los padres hicieron ya varias diligencias para coger algún Lacandón, nunca llegaron a ver ni hallaban rastro de posibilidad. En algunos pueblos sucedió coger a unos indios que alborotaban a la gente como Lacandones y eran mozos del mismo pueblo que por hacer burla se ponían como Lacandones desnudos y embijados (Ibid: II, 220).

Es posible que tengamos aquí una prefiguración del papel de los lacandones en las ceremonias del Carnaval, y que éste sea una puesta en escena de un ritual indígena, inspirado por acontecimientos históricos precisos y próximos, cuya significación habría escapado totalmente a los padres españoles.

\section{Una de las principales ceremonias de Bachajón}

El Carnaval, una de las principales ceremonias de Bachajón, es la más completa expresión de la organización centrada sobre los kalpules, representados por los tsumbajonetik. 
a) Si comparamos el Carnaval de Bachajón con los otros carnavales conocidos, principalmente tzotzil y tzeltal, observamos un fuerte contraste entre la rotación de todos los cargos anuales (Zinacantán, Chamula) y la permanencia de ciertos cargos como aquel de $t s^{\prime} u m^{-}$ bajon en Bachajón, cargos sumamente importantes.

En cuanto a otro aspecto, consideramos a Bachajón y Zinacantán en tanto que modelos opuestos. En Zinacantán se trata de una 'inversión" que se puede comparar con la tradición europea del Carnaval, mientras que en Bachajón se trata de un rito de "oposición". En el primer caso en la sociedad invertida persiste la imagen de la sociedad establecida; en el otro, la oposición sugiere una dinámica de la reestructuración, por la intervención de elementos exteriores cuyo soporte es un drama histórico vivido.

b) La organización cuatripartita específica del barrio de San Sebastián en Bachajón, que regula la rotación de los cargos, puede ser confrontada con ejemplos históricos de las tierras bajas, donde se comprueban semejantes principios de organización y/o de rotación. Entre los chol-lacandones en el siglo xvII (Helmuth, 1972) encontramos la existencia de cuatro kalpules teniendo cada uno un jefe permanente y hereditario; de ellos, uno asumía una prioridad con relación a los otros tres. Entre los yucatecos en la época de la Conquista española (Coe, 1965) había representaciones de divinidades que circulaban cada año en el transcurso de las fiestas calendáricas pasando por cuatro secciones comparables a los kalpules de San Sebastián.

\section{Influencia de la Iglesia}

Somos conscientes de haber asistido a eventos rituales de una extrema importancia que han persistido frente a una situación de contacto de cuatro siglos. La misión jesuita renueva actualmente sus esfuerzos para controlar y encauzar las manifestaciones cuya importancia se les había escapado. Durante los cuatro años sucesivos de observación de estas fiestas, la pérdida progresiva de numerosos elementos tradicionales es flagrante e impresionante; éstos han sido reemplazados por ceremonias dentro de la iglesia. La participación de los misioneros en esta fiesta conduce también a una cierta inhibición de los actores. La obligación para los k'abinales de entrar en la iglesia y asistir a las misas, oculta y suprime la dicotomía esencial entre ellos y los responsables de un cargo. Insistiendo en los aspectos rituales del Carnaval, los jesuitas contribuyen a la pérdida de la estructura de la fiesta y por tanto, si esto que nosotros hemos demostrado es exacto, a la desa- 
parición de la tradición tzeltal y de las bases de su organización social propia. ${ }^{17}$ Nosotros no deseamos ciertamente expresar juicios sobre el conjunto de acciones, las cuales son en principio orientadas a la defensa de los indígenas, pero esta intervención corresponde precisamente a la fiesta y sus consecuencias. Por lo tanto, nos parece un hecho importante mostrarlo con objetividad.

\section{BIBLIOGRAFIA}

Aguirre Beltrán, G.

1953 Formas de gobierno indígena. Imprenta Universitaria, México. BecQuelin-Monod, A.

e.p. "Examen de quelques paires sémantiques dans les dialogues rituels des tzeltal de Bachajón (langue maya du Chiapas)". Journal de la Société des Américanistes, París.

"Musique tzeltal du Carnaval de Bachajón: utilisation de la musique dans un rituel d'opposition en pays maya (Htes. Terres du Chiapas)", avec illustrations photographiques et sonores, Ms. déposé au Département d'ethnomusicologie du Musée de l'Homme, París.

BecQuelin-Monod, A. y A. BREToN

1973 Le Carnaval de Bachajón. Journal de la Société des Américanistes, t. 62, 89-130, París.

BRETON, A.

s.f. Bachajón. Contribution à l'étude de l'organisation socio-territoriale et de l'habitat dans une communauté indienne du Chiapas (Mexique). Thèse de Doctorat de 3ème cycle, E.H.E.S.S., París. Ms, 284 p. (1977).

BRICKER, V. R.

1973 Ritual Humor in Highland Chiapas. Texas Pan American Series, Austin y Londres.

CALnek, E. E.

s.f. Comunicación interna (Ms.). Chicago project.

${ }^{17}$ Referente a esta opinión, se encuentra el cuestionario pasado a los alumnos de la misión, bajo el pretexto de interesarlos en su "folklore"; vemos sin dificultad que el énfasis puesto por la Iglesia es completamente ajeno a la estructura de los ritos y que está destinado a formar entre los más jóvenes una interpretación propicia al cristianismo:

1. ¿Cuántas veces van a la iglesia los kabinales, capitanes y principales?

2. ¿Crees que la fiesta sirve para que la gente se reúna, esté contenta?

3. ¿Ayudará la fiesta para que la gente adore a Dios y sirva más a sus hermanos?

4. ¿Cómo preparan la iglesia para la fiesta?

5. Investiga qué personas preparan la iglesia.

6. Dí por escrito qué no estuvo bien de la fiesta. 
Coe, M. D.

1965 "A model of ancient community structure in the Maya Lowlands", Southwestern Journal of Anthropology, Vol. 21, No. 2: 27-114, Albuquerque.

Gossen, G.

1974 Chamulas in the world of the Sun. Time and space in a Maya oral tradition. Harvard University Press, Cambridge.

Guiteras Holmes, C.

1961 Informe sobre Bachajón, Ms., San Cristóbal de Las Casas (Chiapas).

Hellmuth, N.

1972 "Progreso y notas sobre la investigación etnohistórica de las tierras bajas de los siglos xvi y xx", América Indígena, Vol. 32, No. 1: 179-244.

KaUfman, T. S.

1962 "Tzeltal-Tzotzil Comparative Grammar, Part I: Phonology", Microfilm Collection of Manuscripst on American Indian Cultural Anthropology, Serie IX, No. 55: 125-310. University of Chicago Library, Chicago.

LaughLin, R. M.

1973 The Great Tzotzil Dictionnary of San Lorenzo Zinacatan. Smithsonian Institution: Smithsonian Contributions to Anthropology, Washington, D. C.

NASH, J.

$1970^{\circ}$ In the eyes of the ancestors; belief and behavior in a mayan community. Yale University Press, New Haven.

Pozas, R.

1959 Chamula: un pueblo indio de los Altos de Chiapas. Memorias del Instituto Nacional Indigenista, t. VIII, México.

Siverts, H.

1960 "Political organization in a Tzeltal community of Chiapas", Alpha Kappa Deltan, Vol. 30: 14-29.

1969 Oxchuc, una tribu maya de México. Instituto Indigenista Interamericano, Ediciones Especiales No. 52, México.

SLoGum, M.

1965 "The origin of corn and other tzeltal myths", Tlalocan, Vol. 5, No. 1: 1-45, México.

Slocum, M. y F. Gerdel

1971 Vocabulario tzeltal de Bachajón. Instituto Lingüístico de Verano, Serie de Vocabularios Indígenas No. 13, México.

Thompson, J. E. S.

1970 Maya History and Religion. University of Oklahoma Press. Norman.

Villagutierre y Sotomayor, J.

1933 Historia de la Conquista de la Provincia de el Itza... Guatemala. Villa Rojas, A.

1947 "Kinship and nagualism in a Tzeltal community, Southwestern México", American Anthropologist, Vol. 49: 578-588, Menasha. 
Vogt, E. Z.

1969 Zinacantan: A Maya Community in the Highlands of Chiapas. Belknap Press, Cambridge.

XIMÉNeZ, F.

1929-1931 Historia de la Provincia de Chiapa y Guatemala de la Orden. de Predicadores. Guatemala. 